\title{
Hfq, a RNA Chaperone, Contributes to Virulence by Regulating Plant Cell Wall-Degrading Enzyme Production, Type VI Secretion System Expression, Bacterial Competition, and Suppressing Host Defense Response in Pectobacterium carotovorum
}

\author{
Chunting Wang, Tianxin Pu, Wangying Lou, Yujie Wang, Zishu Gao, Baishi Hu, and Jiaqin Fan \\ Department of Plant Pathology, Nanjing Agricultural University, Nanjing 210095, China \\ Accepted 20 May 2018.
}

\begin{abstract}
Hfq is a RNA chaperone and participates in a wide range of cellular processes and pathways. In this study, mutation of $h f q$ gene from Pectobacterium carotovorum subsp. carotovorum PccS1 led to significantly reduced virulence and plant cell wall-degrading enzyme (PCWDE) activities. In addition, the mutant exhibited decreased biofilm formation and motility and greatly attenuated carbapenem production as well as secretion of hemolysin coregulated protein (Hcp) as compared with wildtype strain PccS1. Moreover, a higher level of callose deposition was induced in Nicotiana benthamiana leaves when infiltrated with the mutant. A total of 26 small (s)RNA deletion mutants were obtained among a predicted 27 sRNAs, and three mutants exhibited reduced virulence in the host plant. These results suggest that $h f q$ plays a key role in Pectobacterium virulence by positively impacting PCWDE production, secretion of the type VI secretion system, bacterial competition, and suppression of host plant responses.
\end{abstract}

An essential host factor of the RNA bacteriophage Qbeta, known as Hfq, was first discovered in Escherichia coli a half century ago. In recent decades, Hfq was recognized as a member of a huge family of RNA-binding proteins found in almost every cellular organism from all three domains of life. Hfq belongs to the Sm and Lsm (Sm-like) protein families (Vogel and Luisi 2011) and it has a characteristic feature, i.e., a ring-like hexamer of quaternary multimeric architecture, including central components of messenger (m)RNA splicing machinery, scaffolds for RNA-decapping assembly, protective chaperones of small nucleolar RNAs, ribosomal RNAs, and transfer RNA precursors (Vogel and Luisi 2011). In bacteria, Hfq binds with RNAs and regulates gene expression in

${ }^{\dagger}$ Corresponding author: Jiaqin Fan; E-mail: fanjq@njau.edu.cn

Funding: This work was supported by Special Fund for Agro-Scientific Research in the Public Interest of China (grant number 201303015), China National Key Technology Support Program (2012BAD14B02) and TopNotch Academic Programs Project of Jiangsu Higher Education Institutions (PPZY2015B157).

*The $\boldsymbol{e}$-Xtra logo stands for "electronic extra" and indicates that two supplementary figures and five supplementary tables are published online.

(c) 2018 The American Phytopathological Society posttranscriptional levels or RNA stability, using base-pairing interaction (Papenfort et al. 2013). The Hfq-binding sites for most mRNAs are unknown, but the structures of Hfq-RNA complexes revealed that the proximal and distal faces prefer Urich (Robinson et al. 2014; Wang et al. 2011) and A-rich sequences (Link et al. 2009; Robinson et al. 2014), respectively. Moreover, Hfq could act alone to regulate gene expression (Chao and Vogel 2010), and, in some species, it has been reported that sRNAs could regulate with trans-encoded mRNA targets without an obvious Hfq homolog, which might provide leads for hidden proteins with Hfq-like function (Chao and Vogel 2010; Sharma et al. 2010). Importantly, Hfq regulates virulence in several animal pathogenic bacteria, such as Bordetella pertussis, Listeria monocytogenes, Klebsiella pneumoniae, Vibrio cholerae, Yersinia pestis, E. coli, and Salmonella typhimurium (Bibova et al. 2013; Chiang et al. 2011; Christiansen et al. 2004; Ding et al. 2004; Geng et al. 2009; Kendall et al. 2011; Sittka et al. 2007). Hfq also regulates the production of secondary metabolites to maintain a symbiotic relationship with the host nematodes in Photorhabdus luminescens (Tobias et al. 2017) and to promote symbiosis, competition, virulence, and biocontrol in rhizobacterium Pseudomonas aeruginosa M18 (Wang et al. 2012). However, in plant-pathogenic bacteria, the roles of Hfq remain only partially understood. The first Hfq-associated virulence phenotype was reported by Wilms in Agrobacterium tumefaciens in 2012 (Wilms et al. 2012). A deletion mutant of $h f q$ in Erwinia amylovora Ea1189 significantly reduced virulence in both immature pear fruits and apple shoots (Zeng et al. 2013).

Pectobacterium carotovorum subsp. carotovorum is a bacterial phytopathogen that causes soft rot in several crops and ornamental plants worldwide, resulting in important economic losses (Ma et al. 2007; Mansfield et al. 2012). The secretion of plant cell wall-degrading enzymes (PCWDEs) and their regulatory systems associated with pathogenicity have been well studied (Charkowski et al. 2012; Hassan et al. 2013; Yasuhara-Bell et al. 2016). Although the roles of Hfq and sRNA interactions have been thoroughly examined in some enterobacteria strains (e.g., E. coli and Salmonella typhimurium), little was known about the role of Hfq in $P$. carotovorum subsp. carotovorum. In the present study, the $h f q$ gene was found in P. carotovorum subsp. carotovorum PccS1 from a whole-genome sequencing analysis (unpublished). Phenotypic observations, quantitative reverse transcription-polymerase chain reaction (qRT-PCR), Western blotting, and RNA-seq analyses revealed that the $h f q$ gene in $P$. carotovorum subsp. carotovorum 
positively impacted expression of virulence-associated and some other related genes at the transcriptional level, and it also affected virulence, production of PCWDEs, and carbapenem, secretion of the type VI secretion system (T6SS), and responses to the host plant.

\section{RESULTS}

\section{Hfq is crucial to the virulence}

of $P$. carotovorum subsp. carotovoroum PccS1.

$P$. carotovorum subsp. carotovorum PccS1 was originally isolated from soft rotted leaves of colored calla (Zantedeschia elliotiana) in Nanjing, China in 2007 (Gu et al. 2009). The fulllength sequence of the $h f q$ gene was obtained from the wholegenome sequencing, and an alignment of the deduced $\mathrm{Hfq}$ amino acid sequence was obtained (Fig. 1A). The deduced amino acid sequence exhibited $94 \%$ identity with the Hfq sequence from $P$. atrosepticum SCRI1043. When compared with other species from Enterobacteriaceae, Vibrionaceae, Pseudomonadaceae, Burkholderiaceae, and Xanthomonadaceae families, the sequence exhibited 82 to $93 \%$ similarity (Fig. 1A). Similar to other bacterial Hfq proteins, Hfq from PccS1 contained conserved Sm1 and Sm2 motifs (Fig. 1A).
To demonstrate the roles of $\mathrm{Hfq}$ in $\mathrm{PccS} 1$ virulence, genedeletion mutant $\Delta h f q$ was constructed, and the pBBR vector (with or without the $h f q$ fragment) was introduced into the $h f q$ mutant. Growth of the mutant in Luria Bertani (LB) broth did not differ from the wild-type PccS1, but growth of the $h f q$ mutant in minimal medium (MM) was significantly reduced in stationary phase as compared with the wild-type strain (Supplementary Fig. S1). Virulence assays in the leaves of Chinese cabbage (Brassica rapa subsp. pekinensis), calla lily (Z. aethiopica), and colored calla (Z. elliotiana) indicated that the $h f q$ mutant was almost nonpathogenic, whereas the wild-type strain caused dramatic rot symptoms in plant tissues $12 \mathrm{~h}$ after inoculation (hai). The reduced virulence of the $h f q$ mutant could be fully restored (Fig. 1B). Statistical analyses of the lesion areas revealed significant differences in virulence between the $h f q$ mutant and the wild-type strain PccS1 (Fig. 1C).

Hfq positively impacts PCWDEs and production of carbapenem, motility, and biofilm formation.

In previous studies, researchers found that PCWDEs, including proteases, pectate lyases, and cellulases, were the key virulence determinants of many phytopathogenic bacteria (Charkowski et al. 2012; Joshi et al. 2016; Mansfield et al.

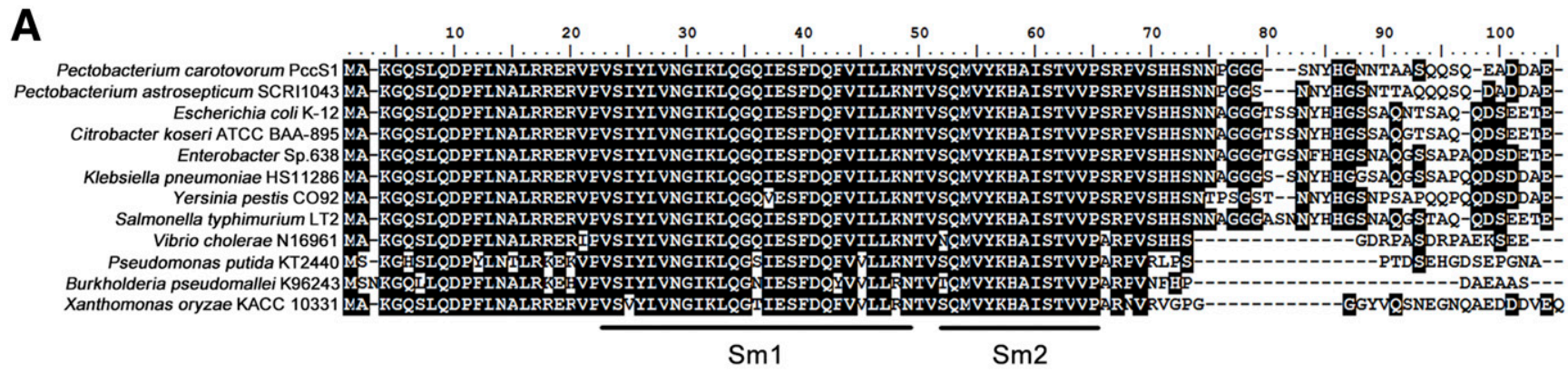

B

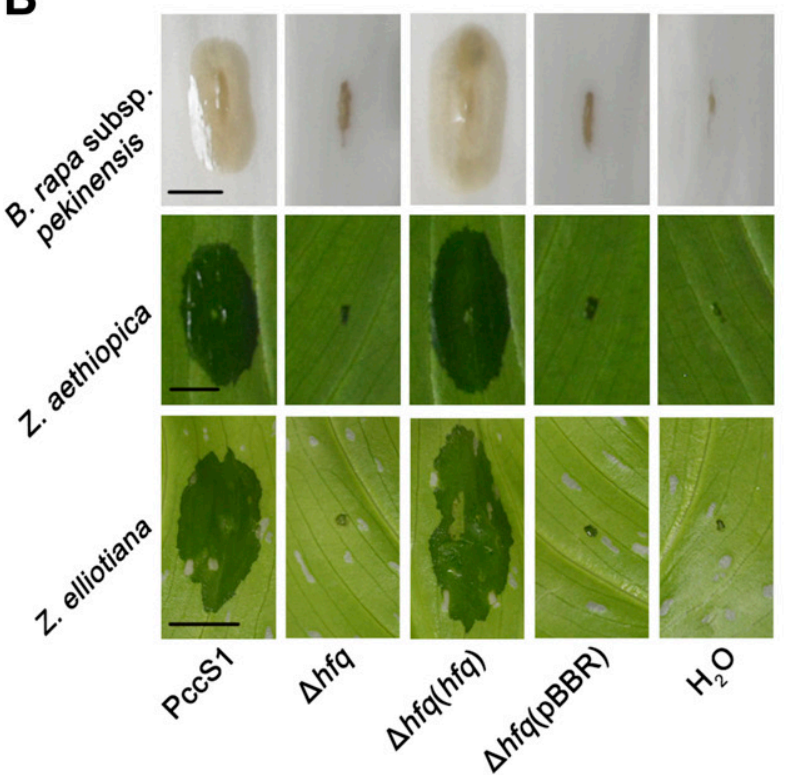

C

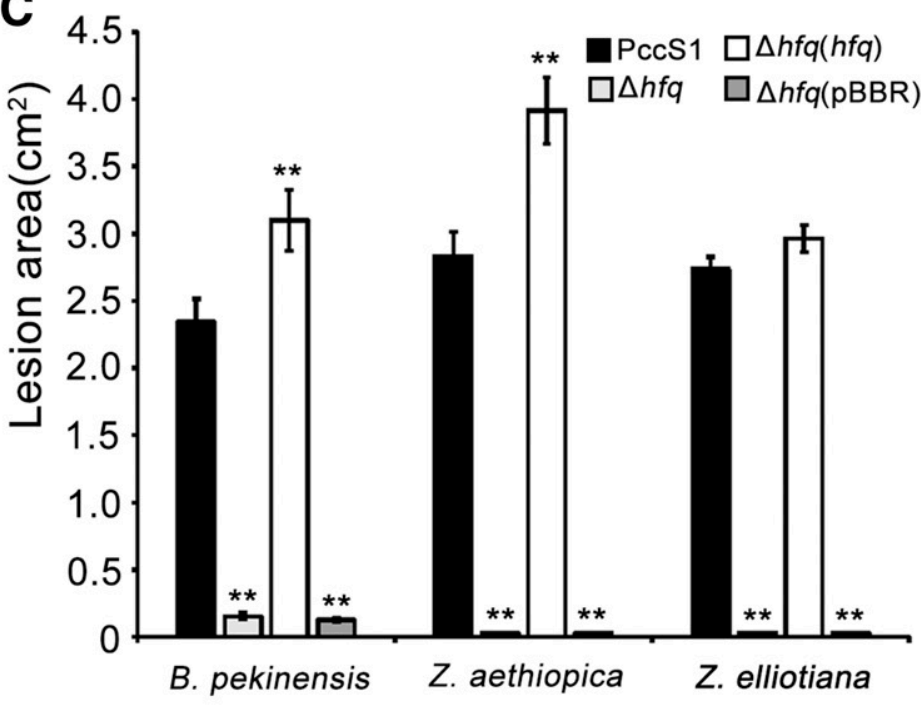

Fig. 1. Deduced amino acid sequence of Hfq and virulence of the wild-type PccS1 and the mutants in Pectobacterium carotovorum subsp. carotovorum. A, Alignment of deduced amino acid sequences of Pectobacterium carotovorum subsp. carotovorum PccS1 Hfq with homologs from other bacterial strains in accordance with the National Center for Biotechnology Information. B, Tissue macerations of P. carotovorum subsp. carotovorum strains: PccS1 (wild-type), $\Delta h f q$ (gene deletion mutant), $\Delta h f q(h f q)$ ( $\Delta h f q$ complemented with the $h f q$ fragment), $\Delta h f q(\mathrm{pBBR})$ ( $\Delta h f q$ complemented with an empty vector carrying plasmid pBBR). Leaves of Chinese cabbage (Brassica rapa subsp. pekinensis), calla lily (Zantedeschia aethiopica), and colored calla (Z. elliotiana) were inoculated with $10 \mu \mathrm{l}$ of diluted bacterial cells (optical density at $600 \mathrm{~nm}=1.2$ ) from cultures suspended in sterilized water. Leaves were inoculated with sterilized water as a negative control. Photographs were taken $16 \mathrm{~h}$ after inoculation (hai). Bar $=1.0 \mathrm{~cm}$. $\mathbf{C}$, Bars represent the maceration areas measured 16 hai. The data are shown as averages \pm standard deviation (asterisks $[* *]$ indicate $P<0.01$, versus the wild-type PccS1; Duncan's multiple range test). 
2012). PCWDE activity assays showed that the $h f q$ mutant exhibited significantly reduced pectate lyase (Pel) and cellulase (Cel) activities as compared with the wild-type PccS1 (Fig. 2A, $\mathrm{B}$, and D) and showed almost no protease activity (Prt) (Fig. 2C and D). Enzyme activities were completely restored when the mutant was complemented (Fig. 2A to D). qRT-PCR analyses showed that expression of prtW, celV, and pell (encoding proteases, cellulases, and pectate lyases) decreased about 9, 4, and 1.5-fold, respectively, in the mutant as compared with the wild-type PccS1 (Fig. 2E). Previous studies indicated that at least three known genes ( $r s m A, k d g R$, and hexA) regulate the production of the PCWDEs in $P$. carotovorum subsp. carotovorum (Charkowski et al. 2012). Results of qRT-PCR analyses indicated that hexA expression was significantly increased in the absence of $h f q$, and expression of $r s m A$ and $k d g R$ was not altered significantly, whereas expression of both $f l h C$ and $f l h D$ decreased drastically (Fig. 2F). Western immunoblotting results further confirmed those of the qRT-PCR results (Fig. 2G).

It has been reported that $P$. carotovorum subsp. carotovorum produces carbapenem (Car), an antibiotic that inhibits the

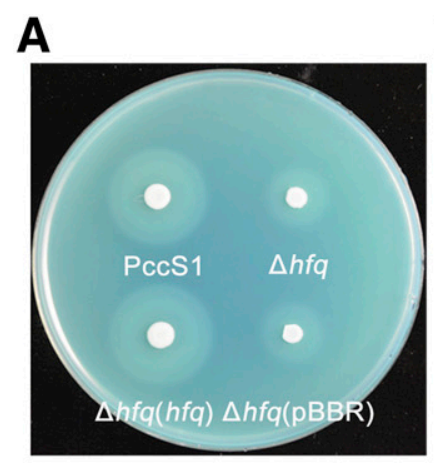

D

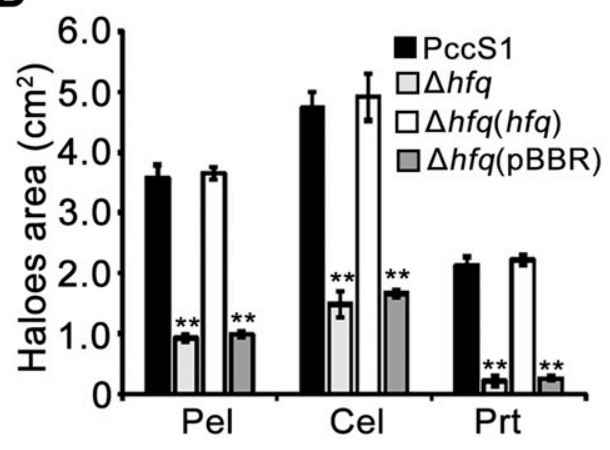

$\mathbf{F}$

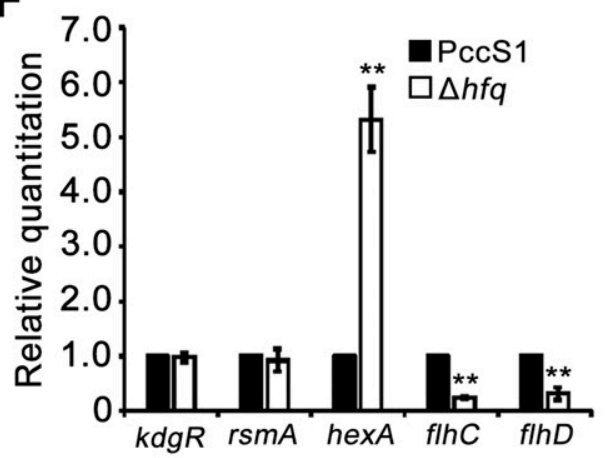

H

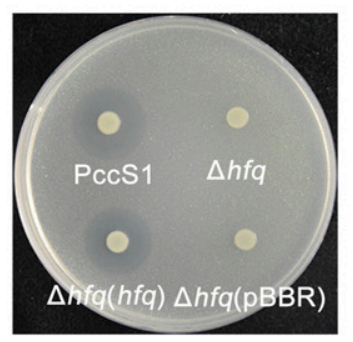

I

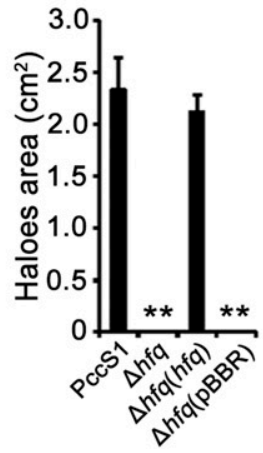

C

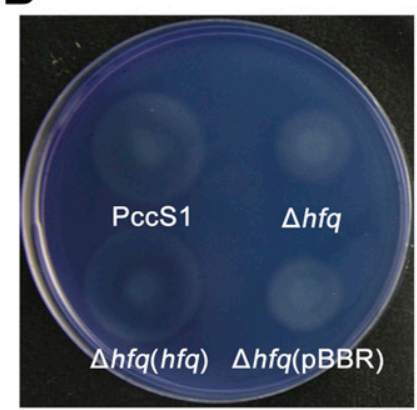

E

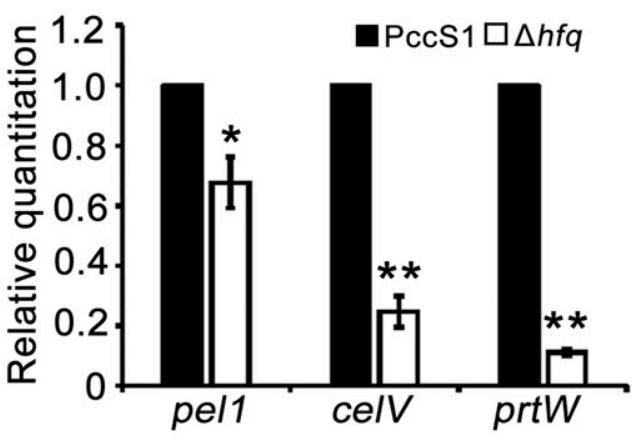

G

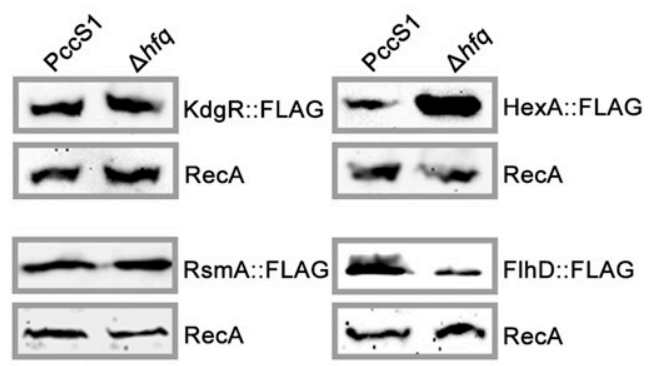

J

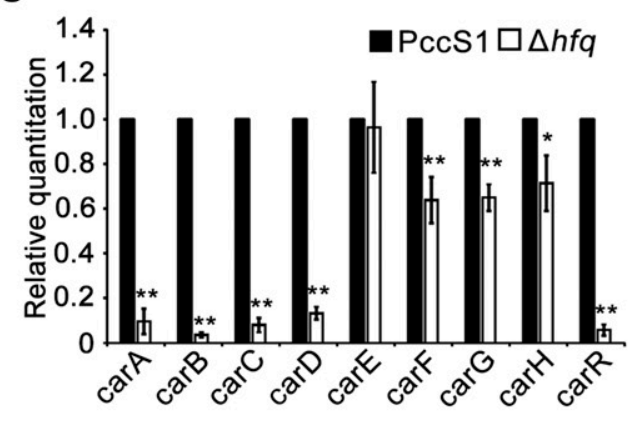


growth of environmental bacteria, thus enhancing its competitive capacity during the infection process (Barnard et al. 2007; Coulthurst et al. 2005). A carA-H operon for Car synthesis and intrinsic resistance is present in the genome, and these genes are regulated by CarR, a LuxR-type regulator (Barnard et al. 2007; Coulthurst et al. 2005). In the present study, a cross-feeding assay to detect Car production was performed. Results indicated that Car production was significantly decreased in the $h f q$ mutant and could be restored when the mutant was complemented (Fig. $2 \mathrm{H}$ and I). Expression levels of the Car biosynthetic genes carA, $\operatorname{car} B, \operatorname{car} C$, and $\operatorname{car} D$, as well as the regulatory gene $\operatorname{car} R$, in the mutant were reduced to about $1 / 10,1 / 29,1 / 13,1 / 8$, and 1/18, respectively, that of the wild-type strain (Fig. 2J).

Motility is an important virulence determinant in P. carotovorum subsp. carotovorum and many other pathogenic bacteria (Wang et al. 2009). In the present study, the $h f q$ mutant exhibited almost nonswimming motility on MM plates containing $0.3 \%$ agar (Fig. $3 \mathrm{~A})$ and cells of the mutant precipitated quickly when transferred to glass tubes after being cultured to an optical density at $600 \mathrm{~nm}$ $\left(\mathrm{OD}_{600}\right)$ of 2.0 (Fig. 3B). The reduced motility phenotype of the $h f q$ mutant was partly restored when complemented (Fig. 3A and B).

Similarly, biofilm formation in the $h f q$ mutant decreased to approximately $20 \%$ that of the wild-type PccS1 (Fig. 3C and D) and could be restored when complemented.

\section{Hfq suppresses pathogen-associated molecular patterns (PAMP)-induced callose deposition in host plant cells.}

PAMP can activate plant intrinsic defense responses, including callose-associated cell-wall modification (Hauck et al. 2003; Kim et al. 2011). To find out whether there was any difference between PccS1 and the $h f q$ mutant in forming PAMP-induced callose deposition of plant cells, the wild-type PccS1 and the

Fig. 2. The activity of plant cell wall-degrading enzymes (PCWDEs) and production of carbapenem were assayed in Pectobacterium carotovorum subsp. carotovorum strains. PCWDE activities were determined visually as follows. A, Production of double haloes around colonies for pectate lyase (Pel), B, an offwhite halo on a dark background around colonies for cellulose (Cel), and $\mathbf{C}$, a clear halo on an opaque background around colonies for protease (Prt), $48 \mathrm{~h}$ after the bacterial cells were patched onto the assay plates. D, Bars indicate halo areas of Pel, Cel, Prt produced by the wild-type PccS1 and mutants. E and F, Bars represent relative messenger (m)RNA levels of genes encoding PCWDEs (pell, celV, and prtW), regulatory proteins $(k d g R, r s m A, h e x A, f l h C$, and $f l h D)$ in wildtype PccS1 and $\Delta h f q$. The mRNA levels of these genes in the wild-type PccS1 were set to 1.0 to calculate the relative expression ratio. G, Protein expression levels of the regulatory proteins KdgR-FLAG, RsmA-FLAG, HexA-FLAG, and FlhD-FLAG in the wild-type PccS1 and the $h f q$ mutant. RecA was used as the loading control. H, Activity of carbapenem (Car) produced by the wild-type PccS1 and $\Delta h f q, \Delta h f q(h f q)$, and $\Delta h f q(\mathrm{pBBR})$ mutants that were tested visually, based on a transparent halo around the colonies caused by antibiotic cell killing $24 \mathrm{~h}$ after the cells were patched onto Luria Bertani agar plates mixed with a suspension of Car-sensitive Escherichia coli DH5 $\alpha$ at a concentration of $500 \mu \mathrm{l}$ per petri dish. I, Bars indicate halo areas of Car produced by the wild-type PccS1 and mutants. J, Bars represent relative mRNA levels of genes encoding proteins associated with the synthesis and regulation of Car ( $c a r A-H$ and $c a r R$ ) in the wild-type PccS1 and $\Delta h f q$. The mRNA levels of these genes in the wild-type PccS1 were set to 1.0 to calculate the relative expression ratio. The experiments were repeated three times with at least three internal replicates in each. The data are shown as averages \pm standard deviation $($ one asterisk $[*]$ indicates $P<0.05$, two [**] indicate $P<0.01$, versus the wild-type PccS1; Duncan's multiple range test).
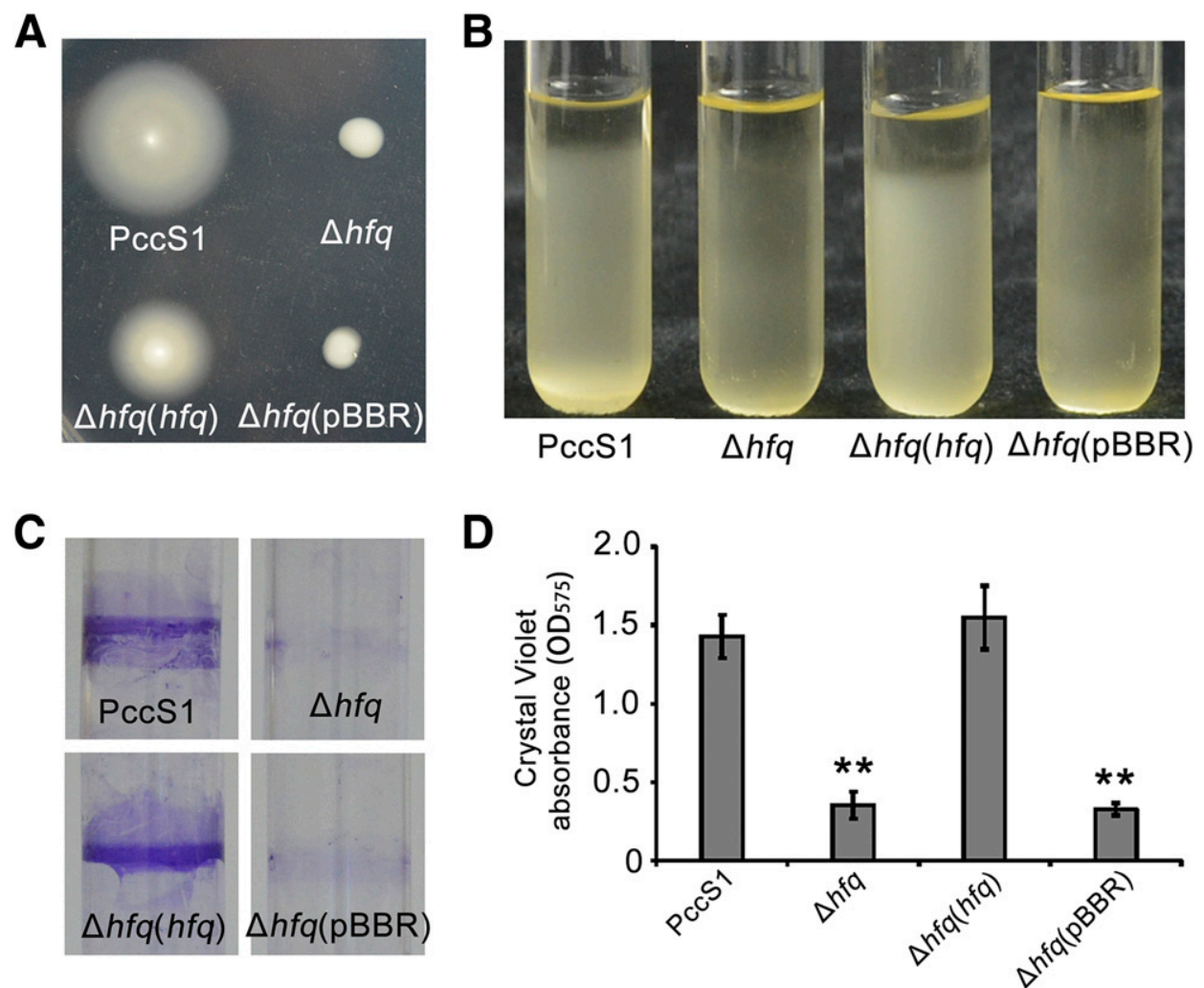

Fig. 3. Hfq effects on motility, biofilm formation, and sedimentation in Pectobacterium carotovorum subsp. carotovorum PccS1. A, The swimming motility of cells visualized as a halo on a clear background at $24 \mathrm{~h}$ after patching on minimal medium plates containing $0.3 \%$ agar. B, Sedimentation of the cells in the glass tubes statically placed for $24 \mathrm{~h}$ at room temperature after being oscillated in Luria Bertani at $28^{\circ} \mathrm{C}$ to an optical density at $600 \mathrm{~nm}$ of 2.0 . C, Biofilm development on an abiotic surface was visualized based on the cells attached on the inner wall of tubes and stained with crystal violet. D, Quantification of the biofilm was measured based on light absorbance at $575 \mathrm{~nm}$ in crystal violet eluted from the inner walls of the tubes. The experiments were repeated three times with at least five internal replicates in each. The data are shown as averages \pm standard deviation (asterisks [**] indicate $P<0.01$, versus the wild-type PccS1; Duncan's multiple range test). 
mutant and complementation strains were infiltrated into $N$. benthamiana leaves, and localized callose deposition in the plant cell at 12 hai was observed by staining the bacteria-infiltrated leaves with aniline blue. Some PAMP-induced callose deposition was observed in $N$. benthamiana leaves infiltrated with the wildtype PccS1 or the complemented strain (Fig. 4A and C) and a much higher level of callose deposition occurred in leaves infiltrated with the mutant (Fig. 4B and D). In addition, PAMPs-induced callose deposition was almost abolished in $N$. benthamiana leaves infiltrated with Pseudomonas syringae pv. tomato DC3000 and sterilized water (Fig. 4E and F), as reported previously (Kim et al. 2011).

\section{Hfq promotes the secretion of Hcp and significantly} activates the expression of the core genes in the T6SS cluster.

It has been reported that the T6SS is a potential virulence factor in some gram-negative bacteria (Lin et al. 2014; Tian et al. 2015), and Hcp is the hallmark of a functional T6SS in many bacterial species. Hcp is a protein with dual functions, one as the T6SS structural component and the other as a direct effector of T6SS. It is delivered into the hosts as a toxin by some animal pathogenic bacteria (Hood et al. 2010; Kapitein and Mogk 2013; Records 2011). To determine whether $P$. carotovorum subsp. carotovorum $h f q$ affects the secretion of T6SS, Hcp-overexpressed strains of the wild-type PccS1, mutant, and complementation strains were constructed by introducing a plasmid carrying the $h c p$ gene fused with an epitope (DYKDDDDK) at the C-terminus. Western blotting results showed that secretion of Hcp was almost abolished in the $h f q$ mutant and was recovered in the complementation strains as compared with the wild type (Fig. 5A).

To demonstrate how Hfq influences the secretion of T6SS and virulence in $P$. carotovorum subsp. carotovorum, mRNA levels of the 17 genes in the T6SS cluster were determined by qRT-PCR. Results showed that transcriptional levels of these genes were all significantly reduced by more than $85 \%$ in the mutant as compared with the wild-type (Fig. 5B).

\section{Hfq globally affects gene expression}

in $P$. carotovorum subsp. carotovorum PccS1.

All the aforementioned results indicated that Hfq plays an important role in regulating $P$. carotovorum virulence. Next, global gene expression of the wild-type PccS1 and the $h f q$ mutant was compared using RNA-seq analyses at the
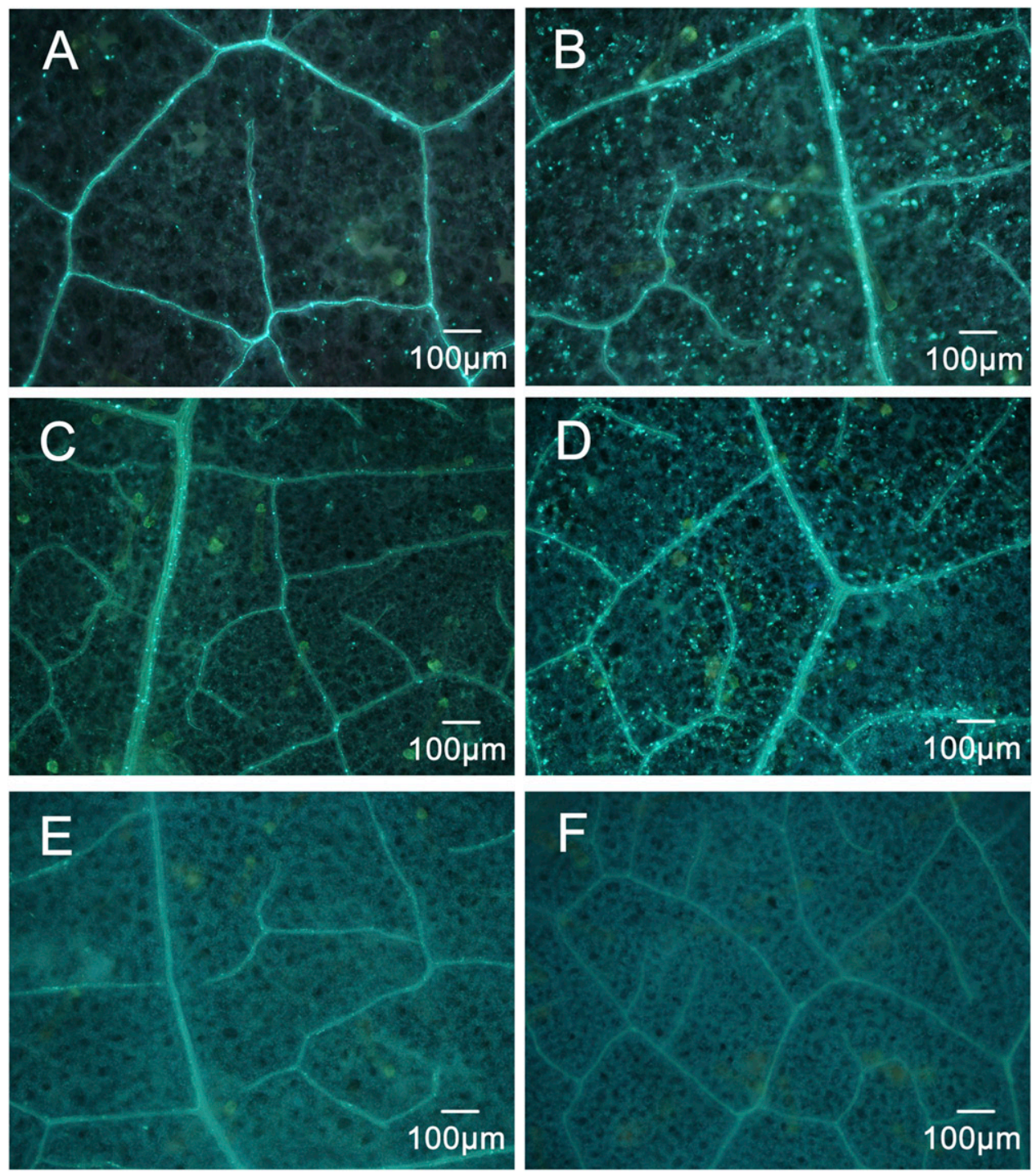

Fig. 4. Callose deposition in the Nicotiana benthamiana leaves infiltrated with bacterial strains. Portions of the N. benthamiana leaves were stained with aniline blue for callose deposition at $12 \mathrm{~h}$ after infiltration of the bacterial cells $\left(10^{8} \mathrm{CFU} \cdot \mathrm{ml}^{-1}\right)$. A, Pectobacterium carotovorum subsp. carotovorum wild-type strain PccS1, B, $\Delta h f q, \mathbf{C}, \Delta h f q(h f q), \mathbf{D}, \Delta h f q(\mathrm{pBBR}), \mathbf{E}$, Pseudomonas syringae pv. tomato DC3000, and $\mathbf{F}$, sterilized water as a negative control. The experiments were repeated three times with at least five internal replicates in each. 
midexponential growth phase. A total of 452 of 4,419 genes (approximately 10\%) exhibited significantly differential expression ( $\geq 2$ fold) at the transcript level in the $h f q$ mutant as compared with PccS1. Among the 452 Hfq-regulated genes, 134 genes were upregulated and 318 genes were downregulated. These results suggest that Hfq more often acts as an activator than as a repressor in $P$. carotovorum. Further analysis revealed that the $452 \mathrm{Hfq}$-dependent genes belonged to at least 16 functional categories (Fig. 6), including lipid transport and metabolism (16.0\%), carbohydrate transport and metabolism (15.2\%), energy production and conversion (12.9\%), inorganic ion transport and metabolism $(9.2 \%)$, and general function prediction (9.0\%) (Fig. 6). In addition, results of qRT-PCR analyses of genes associated with Hfq-mediated regulation, including PCWDEs (pel1, PccS1_0814; celV, PccS1_3690; prtW, PccS1_2900), regulatory proteins (hexA, PccS1_4093), Car synthesis and regulation (carA, PccS1_0882; carB, PccS1_0881; carC,PccS1_0880; carD, PccS1_0879; carR, PccS1_0883), were consistent with the RNA-seq data (Supplementary Table S1).
Three sRNAs (ArcZ, CsrB, and SraG) regulate virulence in PccS1.

Based on the complete genome sequence of $P$. carotovorum subsp. carotovorum PccS1, 27 sRNAs were predicted, using Rfam. The sequences of the 27 sRNAs and differential expression of sRNAs in the $h f q$ deletion mutant versus that of wild-type PccS1 by qRT-PCR are listed in Supplementary Table S2. To analyze the role of sRNAs in the virulence of PccS1, 26 deletion mutants of the predicted sRNAs were constructed and were tested in the host plant. Results indicated that three mutants $(\operatorname{arc} Z$, $\Delta c s r B$, and $\Delta s r a G$ ) were significantly attenuated in virulence, whereas other mutants did not alter in virulence (Fig. 7A and B).

\section{DISCUSSION}

Hfq is required for $P$. carotovorum subsp. carotovorum to grow in MM and for virulence.

It has been demonstrated that Hfq participates in a wide range of cellular processes and pathways, including regulation of translation by sRNA, resistance to various environmental
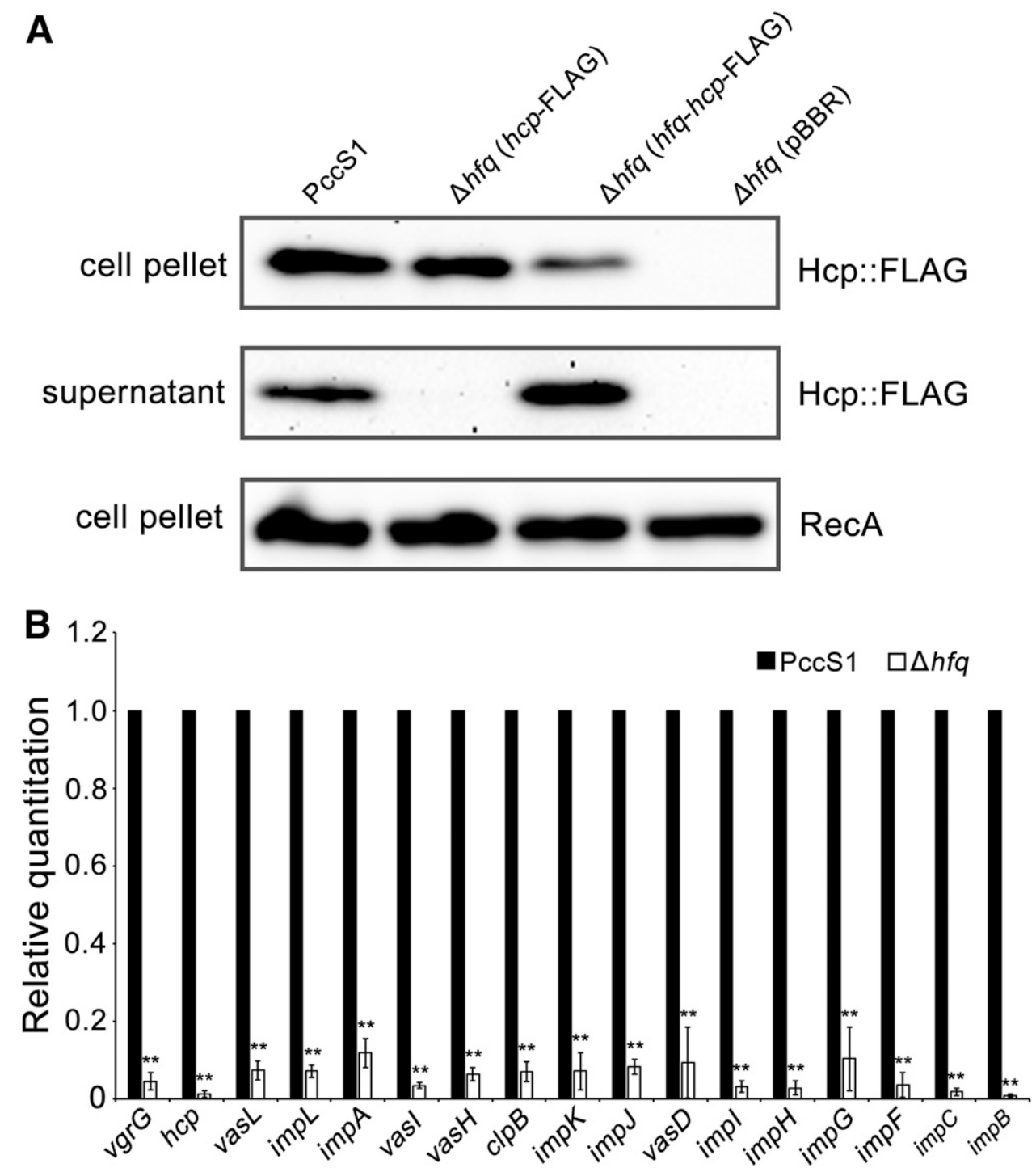

Fig. 5. Effects of Hfq on functional type VI secretion system (T6SS) in Pectobacterium carotovorum subsp. carotovorum. A, Western blot analyses of the supernatant and cell pellet of $h c p:$ :flag fusion strains of the wild-type PccS1, the $h f q$ mutant, and the complementation strain. RecA was used as the loading control. B, Bars indicate relative messenger (m)RNA levels of genes in the cluster of the T6SS in the wild-type PccS1 and the $h f q$ mutant. The mRNA levels of these genes in the wild-type were set to 1.0 to calculate the relative expression ratio. The experiments were repeated three times with at least five internal replicates in each. The data are shown as averages \pm standard deviation (asterisks [**] indicate $P<0.01$, versus the wild-type PccS1; Duncan's multiple range test). 
stresses, cellular metabolism, and virulence (Cui et al. 2013; Feliciano et al. 2016; Sonnleitner and Bläsi 2014; Wroblewska and Olejniczak 2016). In the present study, Hfq is involved in $P$. carotovorum for growth in amino acid limiting conditions, as reported in many animal and plant pathogenic bacteria that showed a growth defect in the absence of Hfq, such as Listeria monocytogenes, Brucella melitensis, Agrobacterium tumefaciens (Christiansen et al. 2004; Cui et al. 2013; Wilms et al. 2012). This growth defect of both the wild-type and the $h f q$ mutant in MM might result from the limitation of carbon resource. Meanwhile, it might also result from improved concentration of metal ions in MM, same as the lower growth rate of Proteus mirabilis cultured in LB supplemented with $\mathrm{NaCl}$ at $5 \%$ (Wang et al. 2014). The decreased growth rate of the $h f q$ mutant did not influence the cell density to reach the threshold level of infection, but the virulence of the $h f q$ mutant was almost nonpathogenic (Fig. 1B). It indicated that Hfq was fully required for virulence in $P$. carotovorum subsp. carotovorum.

\section{Hfq influences PCWDE production and virulence through activation of FlhDC, which represses HexA in $P$. carotovorum subsp. carotovorum.}

Researchers have shown that PCWDEs are key virulence determinants in $P$. carotovorum subsp. carotovorum and other soft-rot Enterobacteriaceae, including $P$. atrosepticum and Dickeya dadantii (Charkowski et al. 2012; Toth et al. 2003). In this study, we found that Hfq significantly promoted the production of PCWDEs (Fig. 2A to $\mathrm{C}$ and $\mathrm{E}$ ), and this is the first evidence of the role of $\mathrm{Hfq}$ in the PCWDE production. We speculate that Hfq regulates the production of PCWDEs, thus acting as a virulence determinant in $P$. carotovorum subsp. carotovorum.

Researches have also shown that expression of the PCWDE genes is negatively regulated by $\operatorname{rsm} A, k d g R$, and $h e x A$ in P. carotovorum subsp. carotovorum (Charkowski et al. 2012; Cui et al. 2008; Liu et al. 1999; Mukherjee et al. 1998). Researchers further indicated that the hexameric complex $\left(\mathrm{FlhD}_{4} \mathrm{C}_{2}\right)$, comprised of the products of the master regulatory flagellar genes $f l h C$ and $f l h D$, negatively regulates the expression of hexA (Charkowski et al. 2012; Chatterjee et al. 2009;
Cui et al. 2008), and the complex activates the production of PCWDEs in P. carotovorum subsp. carotovorum Ecc71 (Cui et al. 2008) and prodigiosin in Serratia sp. strain ATCC 39006 (Hampton et al. 2016). Our data (Fig. 2F) suggest the following molecular regulatory pathway of Hfq required for virulence in $P$. carotovorum subsp. carotovorum $\mathrm{PccS} 1$ (Fig. 8): i) Hfq negatively regulates the expression of hexA and positively regulates $f l h C D$ and ii) the altering of these two regulatory proteins contributes to the production of PCWDEs.

Moreover, in previous studies, flagellar motility and biofilm formation were characterized as accessory virulence determinants in many animal and plant bacterial pathogens, including P. carotovorum subsp. carotovorum (Cui et al. 2008; Esquivel and Pohlschroder 2014; Gauger et al. 2007; Horne et al. 2016; Schiano et al. 2010; Siryaporn et al. 2014). In this study, our results are consistent with those reported previously in Serratia sp. strain ATCC 39006 (Hampton et al. 2016). Though the hypermotility of Yersinia pseudotuberculosis was observed on semisolid agar plates in the absence of $h f q$, it was confirmed that the hypermotility might not be mediated through changes in flagellar expression (Schiano et al. 2010). In addition, evidence supporting the role of twitching motility in biofilm formation was found in Peudomonas aeruginosa (O'Toole and Kolter 1998a), and surface attachments induce Peudomonas aeruginosa virulence (Siryaporn et al. 2014). Here, the extremely reduced biofilm formation and swimming motility of the $h f q$ mutant further demonstrated that Hfq is important for virulence in $P$. carotovorum subsp. carotovorum.

\section{Hfq regulates Car biosynthesis \\ in $P$. carotovorum subsp. carotovorum.}

Car, a $\beta$-lactam antibiotic, is isolated from gram-negative bacteria, including $P$. carotovorum subsp. carotovorum, Serratia sp. strain ATCC39006, and Photorhabdus luminescens TT01 (Coulthurst et al. 2005). The carA-H operon, which is responsible for Car production and intrinsic resistance, has been found in some $P$. carotovorum subsp. carotovorum strains and in Serratia sp. strain ATCC39006 (Coulthurst et al. 2005). This operon is controlled by a LuxR-type transcriptional

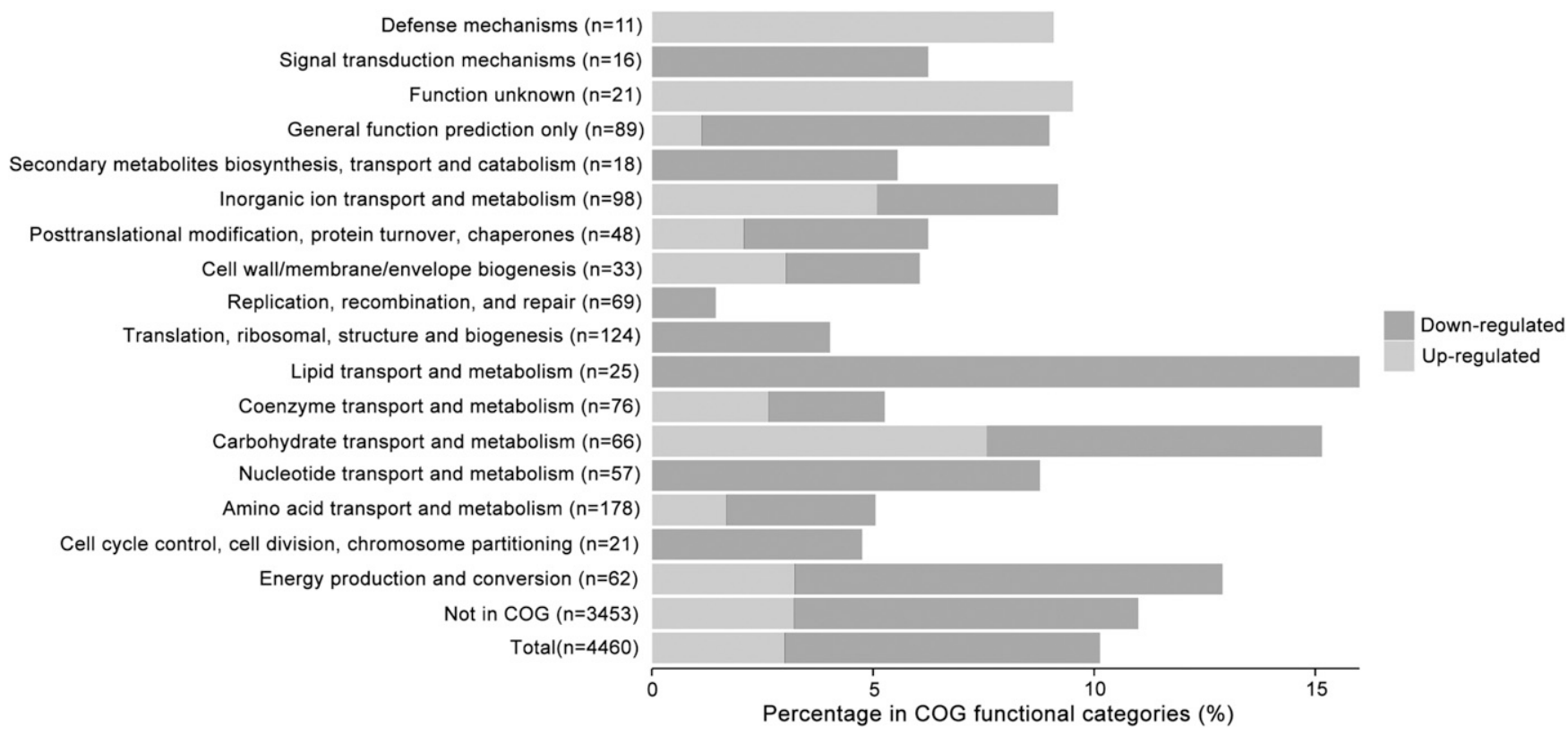

Fig. 6. Functional classification of Hfq-dependent genes in Pectobacterium carotovorum subsp. carotovorum analyzed using RNA-seq. A total of 452 Hfqdependent genes were grouped into different functional classes. Bars represent the percentages of genes from different functional categories from the total number of differentially expressed genes in $\Delta h f q$ compared with those of the wild-type PccS1. 
activator that is encoded by $\operatorname{car} R$ upstream of the operon (Barnard et al. 2007). Genome sequencing of $P$. carotovorum subsp. carotovorum $\mathrm{PccS} 1$ indicated that it possesses entire genes associated with the operon and carR. Our results suggest that Hfq is essential for the production of Car in P. carotovorum subsp. carotovorum PccS1, as reported in Serratia sp. strain ATCC39006 (Wilf et al. 2013). It has been demonstrated that Car aids the promotion of environmental competitive activities during the infection process (Barnard et al. 2007; Coulthurst et al. 2005). A consequence of Car production suggests that Hfq is also essential for accessory processes associated with virulence in $P$. carotovorum subsp. carotovorum.

\section{Hfq activates T6SS to deliver Hcp}

in $P$. carotovorum subsp. carotovorum.

T6SS was found to be required for the delivery of pathogenicity effector proteins into the host cell (Basler et al. 2013; Gallique et al. 2017; Hood et al. 2010; Kapitein and Mogk 2013; Pukatzki et al. 2006). Additional studies of T6SS function revealed that T6SS is a versatile tool with roles in virulence (de Pace et al. 2011; Mulder et al. 2012; Records 2011). Our data showed that the PccS1 mutant of the T6SS-cluster deletion significantly attenuated virulence in the host plant (unpublished), thus indicating that T6SS plays an important role in $P$. carotovorum subsp. carotovorum virulence. In the present study, our results suggested that inactivated $h f q$ significantly repressed the expression of all core genes in the T6SS cluster (Fig. 5A) and led to complete loss of delivering Hcp (Fig. 5B). Therefore, our results confirmed the important role of Hfq in the virulence of PccS1 by affecting expression of T6SS. However, the regulatory mechanisms underlying the relationship between Hfq and T6SS require further study.

\section{Hfq depresses host cell wall-based defense to promote host leaf maceration in $\boldsymbol{P}$. carotovorum subsp. carotovorum.}

PAMPs can trigger plant defense responses referred to as PAMP-triggered immunity (PTI) and accumulation of callose is a molecular marker for PTI (Boudsocq et al. 2010). Researchers indicated that Peudomonas syringae DC3000 suppressed callose deposition in plant leaves, whereas the effects of $P$. carotovorum WPP14 and the T3SS mutants of WPP14 on PAMP-induced callose deposition were similar, as they were not able to completely inhibit PAMP-induced callose deposition in the host plant of $N$. benthamiana (Kim et al. 2011). Similarly, we found that inoculation of PccS1 slightly induced callose deposition in N. benthamiana leaves (Fig. 4), but a higher level of callose deposition was observed in $N$. benthamiana leaves inoculated with the $h f q$ mutant. These results suggested that $\mathrm{Hfq}$ is involved in the suppression of tobacco cell-wall reinforcement. Thus, decreased virulence in
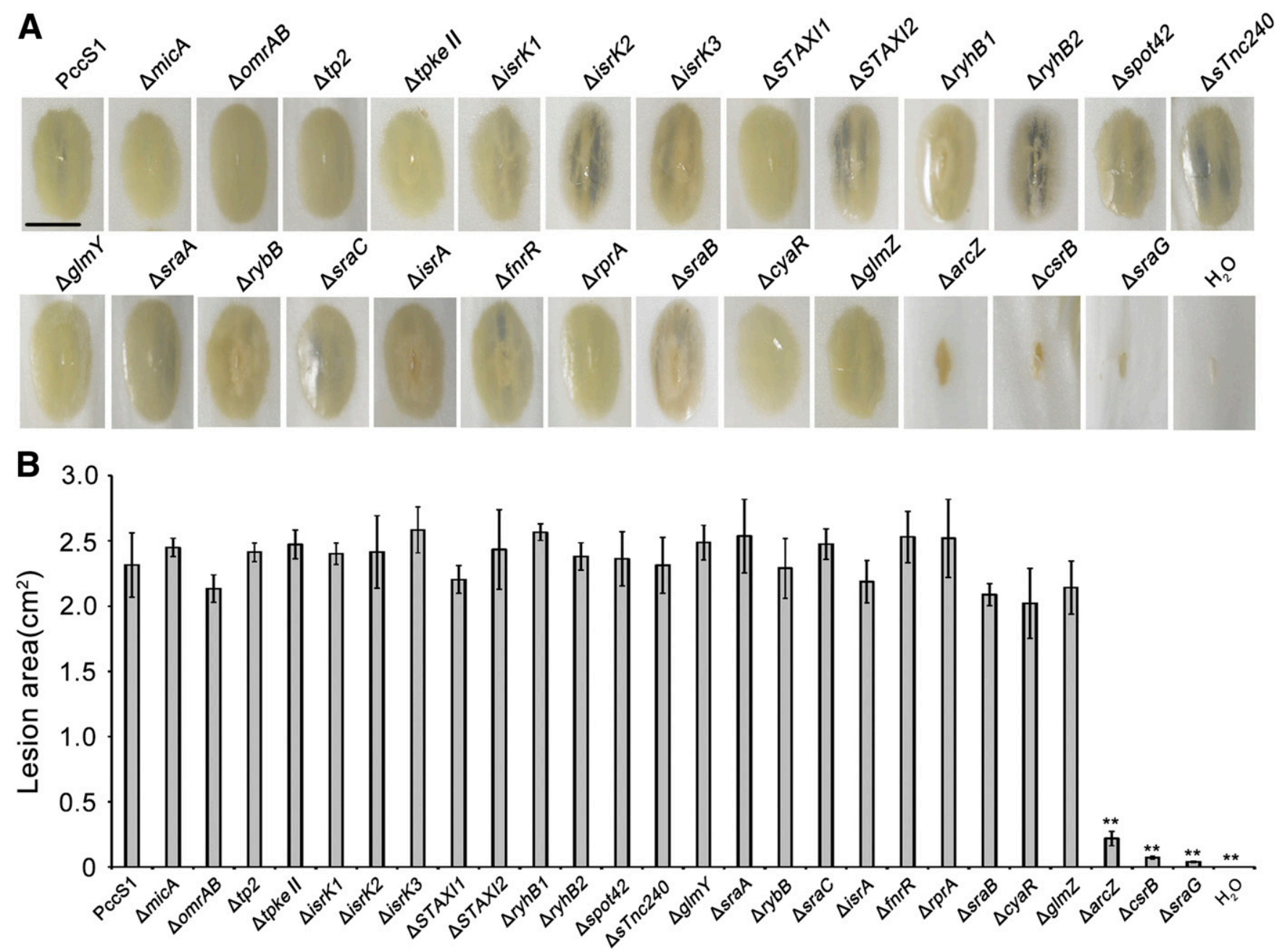

Fig. 7. A, Images indicate the virulence of the wild-type PccS1 and the small RNA individual deletion mutants, as determined on the leaves of Chinese cabbage (Brassica rapa subsp. pekinensis). Photographs were taken $16 \mathrm{~h}$ after inoculation. Bar $=1.0 \mathrm{~cm}$. B, Maceration areas caused by the wild-type PccS1 and the mutants. The virulence assays were conducted three times using five to ten leaf pieces in each assay. The data are shown as averages \pm standard deviation (asterisks $[* *$ indicate $P<0.01$, maceration caused by the mutants versus that by PccS1 on the same host plant; Duncan's multiple range test). 
the $h f q$ mutant may result from the severe impairment of its ability to suppress host cell wall-based defense.

\section{Three sRNAs (ArcZ, CsrB, and SraG) regulate virulence} in a Hfq-dependent or -independent manner in $P$. carotovorum subsp. carotovorum.

Previous studies reported that Hfq-regulated sRNAs (RprA and RyhA) are important for Erwinia amylovora virulence (Zeng et al. 2013). In the present study, we found that three sRNAs (ArcZ, CsrB, and SraG) regulated the virulence of $P$. carotovorum subsp. carotovorum PccS1.

According to previous studies, ArcZ is a conserved, Hfqbinding sRNA and is highly conserved in the $3^{\prime}$ region but more divergent in the $5^{\prime}$ region among some Enterobacteriaceae genera (Supplementary Fig. S2) (Mandin and Gottesman 2010; Papenfort et al. 2009). As many other sRNAs, intracellular accumulation of ArcZ is critically dependent on Hfq at the level of transcript stability (Papenfort et al. 2009). In the present study, Hfq might regulate the virulence of $P$. carotovorum by controlling the stability of ArcZ, though the mechanism of $A r c Z$ on virulence regulation requires further study.

CsrB is one of the most abundant sRNAs. The RNA-binding protein CsrA and the sRNAs (CsrB, CsrC) form the conserved Csr system, and it has been indicated that an increase of active CsrA is important under infection conditions in Yersinia pseudotuberculosis (Nuss et al. 2017). In the present work, when Hfq was absent, expression of $\operatorname{crs} A$ (rsmA, PccS1_0073) RNA exhibited a slight decrease only in RNA-seq analysis. A high-level increase of hexA (PccS1_4093) mRNA exhibited in both qRT-PCR and RNA-seq. Research indicated that hexA negatively regulates $\mathrm{CrsB}$ in $P$. carotovorum subsp. carotovorum Ecc71 (Mukherjee et al. 2000) and Hfq mediates regulation of secondary metabolism in Photorhabdus luminescens via HexA (Tobias et al. 2017). Here, we confirm that Hfq negatively regulates HexA to activate $\mathrm{CrsB}$ in $P$. carotovorum infection on host plants, suggesting that Hfq indirectly facilitates CrsB expression.

$\mathrm{SraG}$, an antisense RNA, is encoded between rpsO (PccS1_1880) and pnp (PccS1_1881) genes (encoding ribosomal protein S15 and PNPase, respectively) in $P$. carotovorum subsp. carotovorum, which is similar in E. coli and some other bacteria (Fontaine et al. 2016; Lu et al. 2012). It has been demonstrated that SraG controls the expression of S15 and PNPase (Fontaine et al. 2016). In the present work, expression of the rpsO and pnp genes were not changed when the $h f q$ gene was deleted in $P$. carotovorum subsp. carotovorum PccS1, as reported previously (Fontaine et al. 2016; Le Derout et al. 2010). Therefore, Hfq required for virulence might have no relation with $\mathrm{SraG}$ and vice versa.

The other sRNAs with no influence on virulence participate in many other regulatory processes, linking with Hfq directly or indirectly, and further studies in $P$. carotovorum subsp. carotovorum are required.

\section{Conclusion.}

The present study has highlighted the roles of Hfq in the global regulation of virulence factors in the plant pathogen, $P$. carotovorum. Hfq acts as a global regulator to not only regulate key virulence determinants (PCWDEs), but it also regulates Car production, biofilm formation, motility, T6SS, and callose deposition in plant cells. These findings will provide new evidence for our understanding of pleiotropic roles of $\mathrm{Hfq}$ in $P$. carotovorum virulence (Fig. 8).

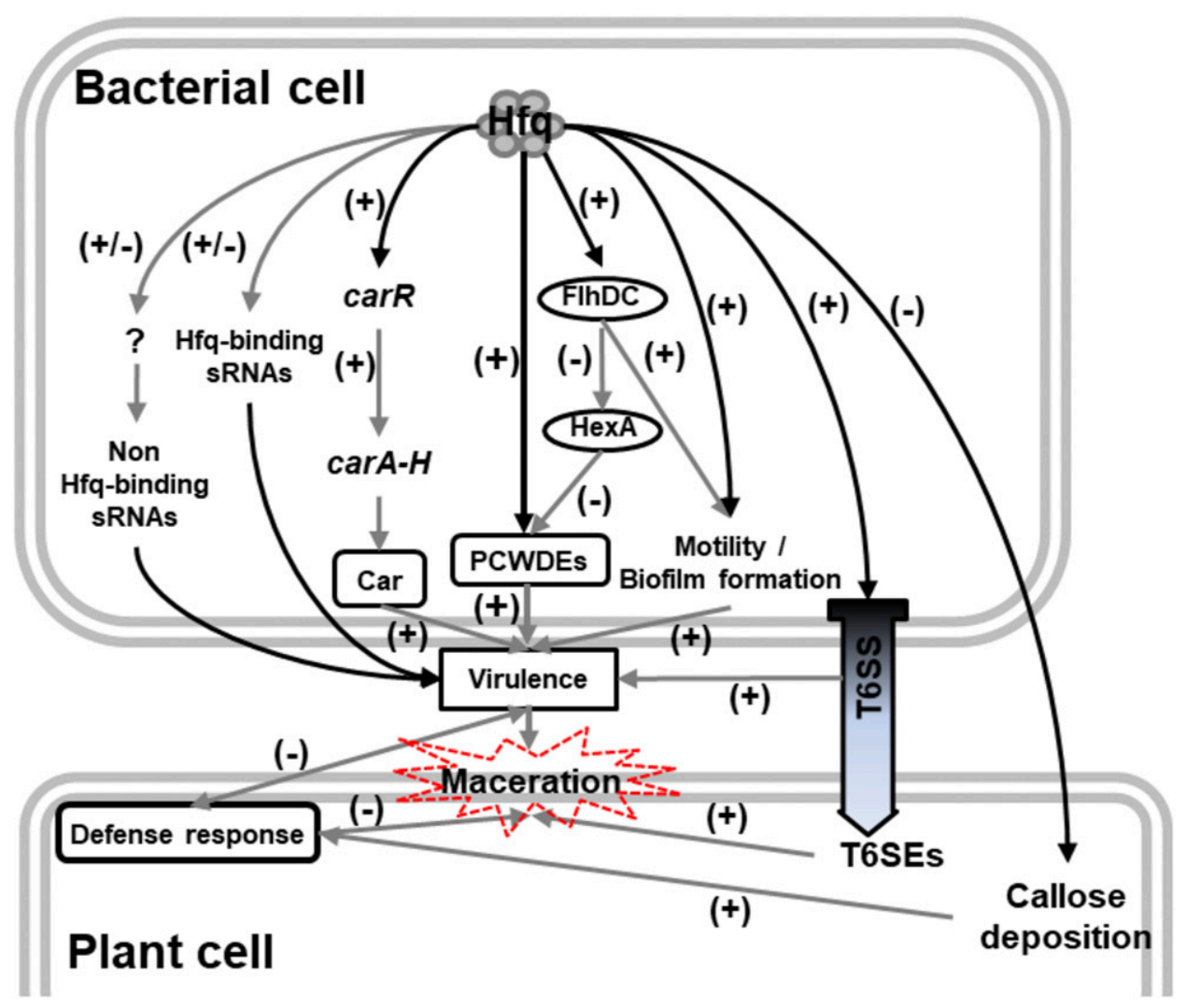

Fig. 8. Summary of the pleiotropic roles of Hfq in the virulence of Pectobacterium carotovorum subsp. carotovorum observed in this study (lines in black) and previous studies (lines in gray). Positive and negative regulation are indicated, respectively, by the presence of (+) or (-) on the line. The question mark (?) indicates that the regulatory mechanisms are unclear or indirect. 


\section{MATERIALS AND METHODS}

Bacterial strains, plasmids, and growth conditions.

The bacterial strains and plasmids used in this study are summarized in Supplementary Table S3. PccS1 and the derivate strains were cultured in LB medium (Wang et al. 2018), LB agar plate (LA), or MM (Kersey et al. 2012) at $28^{\circ} \mathrm{C}$, and E. coli in $\mathrm{LB}$ at $37^{\circ} \mathrm{C}$. When required, the antibiotics were added to the media at the following final concentrations: rifampicin (Rif) at $100 \mu \mathrm{g} \cdot \mathrm{ml}^{-1}$, kanamycin $(\mathrm{Km})$ at $50 \mu \mathrm{g} \cdot \mathrm{ml}^{-1}$, and gentamicin $(\mathrm{Gm})$ at $50 \mu \mathrm{g} \cdot \mathrm{ml}^{-1}$. The OD of the culture was measured by a BioPhotometer (Eppendorf, Hamburg, Germany) at $600 \mathrm{~nm}$.

\section{Mutant construction and complementation.}

Gene knockout mutants were constructed and complemented as previously described (Wang et al. 2018). Briefly, plasmids pEX18Gm carried the 300- to 600-bp fragment cloned from upstream and downstream of the target genes, using the relevant primers (Supplementary Table S4), and were ligated by a $\mathrm{Km}$ cassette amplified from pET30, and then, the recombinant vectors were introduced into $E$. coli $\mathrm{S} 17-1 \lambda$ pir to generate a donor strain. With the wild-type strain PccS1 used as the recipient, transconjugants were constructed by homologous recombination. To select candidate gene-deletion mutants, transconjugants were plated on LB plate containing $10 \%$ sucrose (Solarbio, Beijing, China), $100 \mu \mathrm{g} \cdot \mathrm{ml}^{-1}$ Rif, and $50 \mu \mathrm{g} \cdot \mathrm{ml}^{-1} \mathrm{Km}$. To construct complementation strains, the target gene and its promoter region were amplified and were cloned into pBBR1-MCS5. The generated vector carrying the target gene was introduced into each respective mutant by conjugation, as described above. The complemented strains were selected based on $\mathrm{Gm}$ resistance. All constructs were verified by PCR and sequencing. The complemented strains carrying the target gene fusion with an epitope tagging fragment (DYKDDDDK) at the $\mathrm{C}$ terminus were additionally confirmed by Western immunoblotting for the expected FLAG-tagged protein (de Bruin et al. 2011; Jiang et al. 2017).

\section{Virulence assay.}

Virulence assays were performed as previously described (Andrade et al. 2008; Jiang et al. 2017; Li et al. 2010) on 45day-old leaves detached from Chinese cabbage (Brassica rapa subsp. pekinensis), calla lily (Zantedeschia aethiopica), and colored calla (Z. elliotiana) plants grown in a greenhouse (temperature varying from 22 to $28^{\circ} \mathrm{C}, 16$-h day length, and approximately $80 \%$ relative humidity). The assays were repeated three times using at least five leaf pieces in each.

\section{PCWDE activity and carbapenem assay.}

PCWDE activity assays were essentially performed as previously described (Barnard et al. 2010; Jiang et al. 2017). Briefly, appropriated cultures were harvested and were diluted in $\mathrm{LB}$ broth to an $\mathrm{OD}_{600}$ of 1.0. Two microliters of the cell suspension was spotted onto protease assay plates (LA containing $10 \%$ sterilized skimmed milk) as well as pectate lyase and cellulase assay plates, as previously described (Barnard et al. 2010). PCWDE production was visualized based on haloes that occurred around the bacterial colonies when cells were spotted onto assay plates and incubated for $48 \mathrm{~h}$ at $28^{\circ} \mathrm{C}$. Finally, plates were photographed and areas (in square centimeters) of the haloes were measured. The experiments were repeated three times with at least five replicates in each.

Car assays were performed as described previously (Thomson et al. 1997). Briefly, a 500- $\mu$ l suspension of Car-sensitive E. coli $\mathrm{DH} 5 \alpha\left(\mathrm{OD}_{600}=1.0\right)$ was mixed with LA in each petri dish before solidification, then, a bacterial lawn was formed. Cells of wild-type PccS1 and the mutants were appropriated, cultured, suspended, and adjusted in sterilized water to $\mathrm{OD}_{600}=1.0$. Two microliters of diluted cells was spotted onto the plates with a bacterial lawn. Plates were incubated at $28^{\circ} \mathrm{C}$ for $24 \mathrm{~h}$. When cross-feeding occurred, a clear halo appeared around patched cells, areas (in square centimeters) of the haloes were measured and photographs were taken. The assays were repeated three times with at least five internal replicates in each.

\section{Motility assay.}

Motility of the strains was performed as previously described with some modifications (Fan et al. 2011; Wang et al. 2009). Appropriated cultures of PccS1 and mutants were harvested and were suspended in sterilized water to an $\mathrm{OD}_{600}$ of approximately 1.0. Cell motility was visualized based on swimming haloes on a MM plate (containing agar at $3 \mathrm{~g}$-per liter) $24 \mathrm{~h}$ after $2.5 \mu \mathrm{l}$ of the cell suspension patched onto. Motility was also monitored by observing precipitation rate of the cells. Cells were cultured in $\mathrm{LB}$ at $28^{\circ} \mathrm{C}$ to an $\mathrm{OD}_{600}$ of $2.0,5 \mathrm{ml}$ of the each culture was transferred to glass tubes, and static-placed for $24 \mathrm{~h}$ at room temperature. Finally, sedimentation of the cells was observed and the tubes were photographed. Each motility assay was repeated three times with at least five replicates.

\section{Biofilm formation assay.}

Qualitative observation and quantitative determination of biofilm formation on an abiotic surface were performed using crystal violet, as previously described (Jiang et al. 2017; O'Toole and Kolter 1998b; Zeng et al. 2013). Each assay was repeated three times with at least five replicates.

\section{qRT-PCR.}

Transcript levels of target genes were measured by qRT-PCR as previously described (Jiang et al. 2017; Kersey et al. 2012). Cells of the wild-type PccS1 or mutants were cultured in LB from a $1 \%$ dilution of overnight cultures to an $\mathrm{OD}_{600}$ of 1.0. Three milliliters of the cultures were centrifuge-pelleted at $4^{\circ} \mathrm{C}$. After washing three times in RNA-free water, total RNA of each strain was extracted using the E.Z.N.A. bacterial RNA kit (OMEGA, Norcross, GA, U.S.A.), and $1 \mu \mathrm{g}$ of RNA was then used to synthesize cDNA according to the manufacturer's instructions for the PrimeScript RT reagent (perfect real time) kit (TaKaRa, Dalian, China). The quality and concentration of RNA and cDNA was verified using microspectrophotometer NanoDrop ND-1000 (NanoDrop Technologies, Wilmington, DE, U.S.A.). Then qRT-PCR was performed in an ABI Prism 7500 Sequence Detection System (Applied Biosystems, Carlsbad, CA, U.S.A.), using AceQ qPCR SYBR green master mix (Vazyme, Nanjing, China). Gene-specific primers are listed in Supplementary Table S5. The housekeeping gene recA was used as an endogenous control for assessing expression (Kersey et al. 2012; Wang et al. 2018). Data were analyzed by the ABI 7500 software (v.2.0.6).

\section{RNA-seq.}

RNA samples of the wild-type PccS1 and the $h f q$ mutant that passed the verification of quality and concentration, as the above described in qRT-PCR, were used to generate cDNA libraries using the NEBNext Ultra Directional RNA library prep kit for Illumina (Illumina, San Diego, CA, U.S.A.). The cDNA libraries were purified using AMPure XP beads (Illumina). Quality of cDNA libraries was assessed using a 2100 Bioanalyzer (Agilent Technologies, Santa Clara, CA, U.S.A.), and quantitation of cDNA libraries was determined with ABI 7500 real time PCR system (Applied Biosystems) using KAPA SYBR green fast universal $2 \times$ qPCR master mix kit (Vazyme). Then, pair-end (PE) index libraries were constructed according to the manufacturer's protocol of NEB Next Ultra Directional 
RNA Library Prep Kit for Illumina (Illumina). Libraries with different indexes were multiplexed and loaded on an illumina Hiseq 2500, according to manufacturer's instructions (Illumina). Sequencing was carried out using a $2 \times 125 \mathrm{PE}$ configuration.

Raw reads were first filtered using statistical software Trimmomatic (v. 0.30) to remove low quality sequences and were re-evaluated using software FastQC (v. 0.10.1), and clean reads were then assembled. Reads were mapped back to the transcriptome of PccS1 using the alignment software bowtie2 (2.1.0). The number of mapped clean reads for each unigene was then counted and normalized into a FPKM value (fragment per kilobases per million reads) (Mortazavi et al. 2008). Differentially expressed genes were identified using statistical analysis among the libraries as described previously (Shen et al. 2012). $P$-value threshold in multiple tests was determined by the false discovery rate (FDR) (Benjamini et al. 2001; Liu et al. 2015). In the present study, differential expressed unigenes between the samples of the wild-type PccS1 and the $h f q$ mutant were screened with a threshold of FDR $\leq 0.05$ and an absolute value of $\log _{2}$-fold $\geq 1$ ( Hu et al. 2016; Liu et al. 2015; Wang et al. 2015).

\section{Callose deposition assay.}

Callose deposition in the leaves of Nicotiana benthamiana was essentially performed as previously described (Hann and Rathjen 2007; Kim et al. 2011). The appropriated cultures were pelleted, were washed three times, and were suspended in sterilized water to an $\mathrm{OD}_{600}$ of $1.2\left(10^{8} \mathrm{CFU} \cdot \mathrm{ml}^{-1}\right)$. The suspensions were infiltrated into the leaves of 6-week-old $N$. benthamiana potted plants growing in the greenhouse. The leaves were detached $12 \mathrm{~h}$ after infiltration, were dipped in $95 \%$ ethanol to be cleared of pigment at $37^{\circ} \mathrm{C}$, and were subsequently washed twice in $70 \%$ ethanol and twice in sterilized water. Pigment-cleared leaves were stained in a solution of aniline blue $0.01 \%(\mathrm{wt} / \mathrm{vol})$ in $150 \mathrm{mM} \mathrm{K}_{2} \mathrm{HPO}_{4}(\mathrm{pH} 9.5)$ for $5 \mathrm{~h}$ in the dark. Finally, stained leaves were examined with epifluorescence (Olympus America Inc., Melville, NY, U.S.A.) and were photographed. Sterilized water and Pseudomonas syringae pv. tomato DC3000 were used as controls. Each assay was repeated at least three times with at least three replicates.

\section{Western blot.}

To visualize outside translocation of Hcp interrupted or not in the absence of $h f q$, the plasmid (pBBR1-MCS5) carrying the fragment of $h c p$ fusion with an epitope tagging fragment (DYKDDDDK) at the $\mathrm{C}$ terminus was introduced into the wildtype PccS1 and the $h f q$ mutant, for Western blotting as previously described (Basler et al. 2012; de Bruin et al. 2011; Jiang et al. 2017; Sonnleitner and Bläsi 2014). Overnight cultures were diluted to 1:100 in $25 \mathrm{ml}$ of fresh LB. Cells were harvested by centrifugation at $6,000 \times g$ for $20 \mathrm{~min}$ for intracellular protein assay when $\mathrm{OD}_{600}$ reached 0.8 , while supernatants were collected for extracellular secreted protein assay. Pellets were washed three times in phosphate buffered saline (PBS) and were resuspended in radioimmunoprecipitation assay (RIPA) lysates ( $1 \%$ Triton X-100, $1 \%$ deoxycholte, $0.1 \%$ sodium dodecyl sulfate (SDS), added at $10 \mu$ l per milligram of cells). Phenylmethanesulfonyl fluoride, protease inhibitors, and phosphatase inhibitors were added to the samples at a ratio of $1: 100(\mathrm{vol} / \mathrm{vol})$ of RIPA. The mixture was incubated on ice for $3 \mathrm{~h}$, and then, was centrifuged at $13,000 \times g$ for $5 \mathrm{~min}$. The supernatants were obtained and heated at $98^{\circ} \mathrm{C}$ for $5 \mathrm{~min}$, then dispensed for future analyses. For extraction of secreted proteins, the supernatants of the cultures were passed through a $0.2-\mu \mathrm{m}$ filter to remove bacterial cells. Proteins from the supernatants were precipitated by adding $100 \%$ trichloroacetaic acid to a final concentration of $10 \%$, and were then pelleted by centrifugation $(13,000 \times g)$ at $4^{\circ} \mathrm{C}$ for $20 \mathrm{~min}$. The pellets were washed three times in ice-cold acetone and were resuspended in $1 \times$ PBS. Samples were heated at $98^{\circ} \mathrm{C}$ for $5 \mathrm{~min}$, were dispensed, and were stored at $-80^{\circ} \mathrm{C}$ for further analyses.

Samples were loaded onto a $12 \%$ SDS-polyacrylamide gel (Bio-Rad, Hercules, CA, U.S.A.) for polyacrylamide gel electrophoresis, and were then transferred to a polyvinylidene diflouride membrane (Millipore, Red Bank, NJ, U.S.A.). The membranes were blocked with $5 \%$ milk in Tris-buffered saline containing Tween $0.05 \%$ (TBST, $\mathrm{pH}=7.5$ ) for $1 \mathrm{~h}$ at room temperature, and were hybridized with a 1:5,000 dilution of primary protein antibody, DYKDDDDK-Tag (3B9) Mouse $\mathrm{mAb}$ (Abmart, Berkeley Heights, NJ, U.S.A.) for $2 \mathrm{~h}$ at room temperature with $3 \%$ milk in TBST. The membrane was then washed with TBST for $5 \mathrm{~min}$ three times and was incubated with a 1:10,000 dilution of goat anti-mouse immunoglobulin G-horseradish peroxidase (lgG-HRP) (Abmart) at room temperature for $1 \mathrm{~h}$ and were then washed three times with TBST. Peroxidase was detected by ECL Western blotting substrate (Bio-Rad). The membrane was incubated with a 1:5,000 dilution of goat anti-rabbit lgG-HRP (Abmart), after it had been hybridized with a 1:3,000 dilution of anti-RecA antibody (ab63797) (Abcam, Cambridge, U.K.), which was used as loading control and followed the same steps as above.

\section{sRNA identification and sequence.}

Based on the genome sequence, we used Rfam (GriffithsJones et al. 2005) to identify sRNAs in $P$. carotovorum subsp. carotovorum PccS1. Rfam is a database of noncoding RNAs (ncRNAs) represented by multiple sequence alignments. It aims to facilitate the identification and classification of new members of known sequence families and distributes annotation of ncRNAs. To confirm the sRNAs predicted by Rfam, we also blasted the sequences in the National Center for Biotechnology Information database.

Data were statistically analyzed using SPSS 14.0 (SPSS Inc., Chicago). The hypothesis test of percentages (Duncan's multiple range test, $P=0.05$ or 0.01 ) was used to determine significant difference in the assays described above.

\section{ACKNOWLEDGMENTS}

We would like to thank F. Zhao (University of Illinois) for his critical review of the final manuscript and Z. Cui and G. Qian (Nanjing Agricultural University) for their tools and technical assistance. We also acknowledge the reviewers whose comments and suggestions helped us improve the manuscript.

\section{LITERATURE CITED}

Andrade, A. E., Silva, L. P., Pereira, J. L., Noronha, E. F., Reis, F. B., Jr., Bloch, C., Jr., dos Santos, M. F., Domont, G. B., Franco, O. L., and Mehta, A. 2008. In vivo proteome analysis of Xanthomonas campestris pv. campestris in the interaction with the host plant Brassica oleracea. FEMS Microbiol. Lett. 281:167-174

Barnard, A. M., Bowden, S. D., Burr, T., Coulthurst, S. J., Monson, R. E., and Salmond, G. P. 2007. Quorum sensing, virulence and secondary metabolite production in plant soft-rotting bacteria. Philos. Trans. R. Soc. Lond. B Biol. Sci. 362:1165-1183.

Barnard, A. M., Simpson, N. J., Lilley, K. S., and Salmond, G. P. 2010. Mutations in rpsL that confer streptomycin resistance show pleiotropic effects on virulence and the production of a carbapenem antibiotic in Erwinia carotovora. Microbiology 156:1030-1039.

Basler, M., Ho, B. T., and Mekalanos, J. J. 2013. Tit-for-tat: Type VI secretion system counterattack during bacterial cell-cell interactions. Cell 152:884-894.

Basler, M., Pilhofer, M., Henderson, G. P., Jensen, G. J., and Mekalanos, J. J. 2012. Type VI secretion requires a dynamic contractile phage taillike structure. Nature 483:182-186. 
Benjamini, Y., Drai, D., Elmer, G., Kafkafi, N., and Golani, I. 2001. Controlling the false discovery rate in behavior genetics research. Behav. Brain Res. 125:279-284.

Bibova, I., Skopova, K., Masin, J., Cerny, O., Hot, D., Sebo, P., and Vecerek, B. 2013. The RNA chaperone Hfq is required for virulence of Bordetella pertussis. Infect. Immun. 81:4081-4090.

Boudsocq, M., Willmann, M. R., McCormack, M., Lee, H., Shan, L., He, P., Bush, J., Cheng, S. H., and Sheen, J. 2010. Differential innate immune signalling via $\mathrm{Ca}^{2+}$ sensor protein kinases. Nature 464:418-422.

Chao, Y., and Vogel, J. 2010. The role of Hfq in bacterial pathogens. Curr. Opin. Microbiol. 13:24-33.

Charkowski, A., Blanco, C., Condemine, G., Expert, D., Franza, T., Hayes, C., Hugouvieux-Cotte-Pattat, N., López Solanilla, E., Low, D., Moleleki, L., Pirhonen, M., Pitman, A., Perna, N., Reverchon, S., Rodríguez Palenzuela, P., San Francisco, M., Toth, I., Tsuyumu, S., van der Waals, J., van der Wolf, J., Van Gijsegem, F., Yang, C. H., and Yedidia, I. 2012. The role of secretion systems and small molecules in soft-rot Enterobacteriaceae pathogenicity. Annu. Rev. Phytopathol. 50:425-449.

Chatterjee, A., Cui, Y., and Chatterjee, A. K. 2009. RsmC of Erwinia carotovora subsp. carotovora negatively controls motility, extracellular protein production, and virulence by binding FlhD and modulating transcriptional activity of the master regulator, FlhDC. J. Bacteriol. 191: 4582-4593.

Chiang, M. K., Lu, M. C., Liu, L. C., Lin, C. T., and Lai, Y. C. 2011. Impact of Hfq on global gene expression and virulence in Klebsiella pneumoniae. PLoS One 6:e22248.

Christiansen, J. K., Larsen, M. H., Ingmer, H., Søgaard-Andersen, L., and Kallipolitis, B. H. 2004. The RNA-binding protein Hfq of Listeria monocytogenes: Role in stress tolerance and virulence. J. Bacteriol. 186: 3355-3362.

Coulthurst, S. J., Barnard, A. M., and Salmond, G. P. 2005. Regulation and biosynthesis of carbapenem antibiotics in bacteria. Nat. Rev. Microbiol. 3:295-306.

Cui, M., Wang, T., Xu, J., Ke, Y., Du, X., Yuan, X., Wang, Z., Gong, C., Zhuang, Y., Lei, S., Su, X., Wang, X., Huang, L., Zhong, Z., Peng, G., Yuan, J., Chen, Z., and Wang, Y. 2013. Impact of Hfq on global gene expression and intracellular survival in Brucella melitensis. PLoS One 8:e71933.

Cui, Y., Chatterjee, A., Yang, H., and Chatterjee, A. K. 2008. Regulatory network controlling extracellular proteins in Erwinia carotovora subsp. carotovora: FlhDC, the master regulator of flagellar genes, activates $r s m B$ regulatory RNA production by affecting gacA and hexA ( $\operatorname{lrh} A)$ expression. J. Bacteriol. 190:4610-4623.

de Bruin, O. M., Duplantis, B. N., Ludu, J. S., Hare, R. F., Nix, E. B., Schmerk, C. L., Robb, C. S., Boraston, A. B., Hueffer, K., and Nano, F. E. 2011. The biochemical properties of the Francisella pathogenicity island (FPI)-encoded proteins IglA, IglB, IglC, PdpB and DotU suggest roles in type VI secretion. Microbiology 157:3483-3491.

de Pace, F., Boldrin de Paiva, J., Nakazato, G., Lancellotti, M., Sircili, M. P., Guedes Stehling, E., Dias da Silveira, W., and Sperandio, V. 2011. Characterization of IcmF of the type VI secretion system in an avian pathogenic Escherichia coli (APEC) strain. Microbiology 157: 2954-2962.

Ding, Y., Davis, B. M., and Waldor, M. K. 2004. Hfq is essential for Vibrio cholerae virulence and downregulates sigma expression. Mol. Microbiol. 53:345-354.

Esquivel, R. N., and Pohlschroder, M. 2014. A conserved type IV pilin signal peptide $\mathrm{H}$-domain is critical for the post-translational regulation of flagella-dependent motility. Mol. Microbiol. 93:494-504.

Fan, J. Q., Qian, G. L., Chen, T., Zhao, Y. Q., Liu, F. Q., Walcott, R. R., and $\mathrm{Hu}$, B. S. 2011. The acyl-homoserine lactone (AHL)-type quorum sensing system affects growth rate, swimming motility and virulence in Acidovorax avenae subsp citrulli. World J. Microbiol. Biotechnol. 27: 1155-1166.

Feliciano, J. R., Grilo, A. M., Guerreiro, S. I., Sousa, S. A., and Leitão, J. H. 2016. Hfq: A multifaceted RNA chaperone involved in virulence. Future Microbiol. 11:137-151.

Fontaine, F., Gasiorowski, E., Gracia, C., Ballouche, M., Caillet, J., Marchais, A., and Hajnsdorf, E. 2016. The small RNA SraG participates in PNPase homeostasis. RNA 22:1560-1573.

Gallique, M., Bouteiller, M., and Merieau, A. 2017. The type VI secretion system: A dynamic system for bacterial communication? Front. Microbiol. 8:1454.

Gauger, E. J., Leatham, M. P., Mercado-Lubo, R., Laux, D. C., Conway, T., and Cohen, P. S. 2007. Role of motility and the flhDC Operon in Escherichia coli MG1655 colonization of the mouse intestine. Infect. Immun. 75:3315-3324.

Geng, J., Song, Y., Yang, L., Feng, Y., Qiu, Y., Li, G., Guo, J., Bi, Y., Qu, Y., Wang, W., Wang, X., Guo, Z., Yang, R., and Han, Y. 2009. Involvement of the post-transcriptional regulator $\mathrm{Hfq}$ in Yersinia pestis virulence. PLoS One 4:e6213.

Griffiths-Jones, S., Moxon, S., Marshall, M., Khanna, A., Eddy, S. R., and Bateman, A. 2005. Rfam: Annotating non-coding RNAs in complete genomes. Nucleic Acids Res. 33:D121-D124.

Gu, C., Fan, J., Yang, X., Hu, B., and Liu, F. 2009. Identification of the pathogen and quorum quenching study on bacterial soft rot of colored calla lily. J Nanjing Agric Univ. 32:71-77.

Hampton, H. G., McNeil, M. B., Paterson, T. J., Ney, B., Williamson, N. R., Easingwood, R. A., Bostina, M., Salmond, G. P., and Fineran, P. C. 2016. CRISPR-Cas gene-editing reveals RsmA and RsmC act through FlhDC to repress the SdhE flavinylation factor and control motility and prodigiosin production in Serratia. Microbiology 162:1047-1058.

Hann, D. R., and Rathjen, J. P. 2007. Early events in the pathogenicity of Pseudomonas syringae on Nicotiana benthamiana. Plant J. 49:607-618.

Hassan, S., Shevchik, V. E., Robert, X., and Hugouvieux-Cotte-Pattat, N. 2013. PelN is a new pectate lyase of Dickeya dadantii with unusual characteristics. J. Bacteriol. 195:2197-2206.

Hauck, P., Thilmony, R., and He, S. Y. 2003. A Pseudomonas syringae type III effector suppresses cell wall-based extracellular defense in susceptible Arabidopsis plants. Proc. Natl. Acad. Sci. U.S.A. 100:8577-8582.

Hood, R. D., Singh, P., Hsu, F., Güvener, T., Carl, M. A., Trinidad, R. R., Silverman, J. M., Ohlson, B. B., Hicks, K. G., Plemel, R. L., Li, M., Schwarz, S., Wang, W. Y., Merz, A. J., Goodlett, D. R., and Mougous, J. D. 2010. A type VI secretion system of Pseudomonas aeruginosa targets a toxin to bacteria. Cell Host Microbe 7:25-37.

Horne, S. M., Sayler, J., Scarberry, N., Schroeder, M., Lynnes, T., and Prüß, B. M. 2016. Spontaneous mutations in the $f l h D$ operon generate motility heterogeneity in Escherichia coli biofilm. BMC Microbiol. 16:262.

Hu, P., Tao, J., Cui, M., Gao, C., Lu, P., and Luo, Y. 2016. Antennal transcriptome analysis and expression profiles of odorant binding proteins in Eogystia hippophaecolus (Lepidoptera: Cossidae). BMC Genomics 17:651.

Jiang, H., Jiang, M., Yang, L., Yao, P., Ma, L., Wang, C., Wang, H., Qian, G., Hu, B., and Fan, J. 2017. The ribosomal protein RplY is required for Pectobacterium carotovorum virulence and is induced by Zantedeschia elliotiana extract. Phytopathology 107:1322-1330.

Joshi, J. R., Burdman, S., Lipsky, A., Yariv, S., and Yedidia, I. 2016. Plant phenolic acids affect the virulence of Pectobacterium aroidearum and P. carotovorum ssp. brasiliense via quorum sensing regulation. Mol. Plant Pathol. 17:487-500.

Kapitein, N., and Mogk, A. 2013. Deadly syringes: Type VI secretion system activities in pathogenicity and interbacterial competition. Curr. Opin. Microbiol. 16:52-58.

Kendall, M. M., Gruber, C. C., Rasko, D. A., Hughes, D. T., and Sperandio, V. 2011. Hfq virulence regulation in enterohemorrhagic Escherichia coli O157:H7 strain 86-24. J. Bacteriol. 193:6843-6851.

Kersey, C. M., Agyemang, P. A., and Dumenyo, C. K. 2012. CorA, the magnesium/nickel/cobalt transporter, affects virulence and extracellular enzyme production in the soft rot pathogen Pectobacterium carotovorum. Mol. Plant Pathol. 13:58-71.

Kim, H. S., Thammarat, P., Lommel, S. A., Hogan, C. S., and Charkowski, A. O. 2011. Pectobacterium carotovorum elicits plant cell death with DspE/F but the $P$. carotovorum DspE does not suppress callose or induce expression of plant genes early in plant-microbe interactions. Mol. PlantMicrobe Interact 24:773-786.

Le Derout, J., Boni, I. V., Régnier, P., and Hajnsdorf, E. 2010. Hfq affects mRNA levels independently of degradation. BMC Mol. Biol. 11:17.

Li, Y., Yamazaki, A., Zou, L., Biddle, E., Zeng, Q., Wang, Y., Lin, H., Wang, Q., and Yang, C. H. 2010. ClpXP protease regulates the type III secretion system of Dickeya dadantii 3937 and is essential for the bacterial virulence. Mol. Plant-Microbe Interact 23:871-878.

Lin, J. S., Wu, H. H., Hsu, P. H., Ma, L. S., Pang, Y. Y., Tsai, M. D., and Lai, E. M. 2014. Fha interaction with phosphothreonine of TssL activates type VI secretion in Agrobacterium tumefaciens. PLoS Pathog. 10:e1003991.

Link, T. M., Valentin-Hansen, P., and Brennan, R. G. 2009. Structure of Escherichia coli $\mathrm{Hfq}$ bound to polyriboadenylate RNA. Proc. Natl. Acad. Sci. U.S.A. 106:19292-19297.

Liu, N., Zhang, G., Xu, S., Mao, W., Hu, Q., and Gong, Y. 2015. Comparative transcriptomic analyses of vegetable and grain pea (Pisum sativum L.) seed development. Front. Plant Sci. 6:1039.

Liu, Y., Jiang, G., Cui, Y., Mukherjee, A., Ma, W. L., and Chatterjee, A. K. 1999. $k d g R_{E c c}$ negatively regulates genes for pectinases, cellulase, protease, Harpin ${ }_{\mathrm{Ecc}}$, and a global RNA regulator in Erwinia carotovora subsp. carotovora. J. Bacteriol. 181:2411-2421.

Lu, P., Zhang, Y., Li, L., Hu, Y., Huang, L., Li, Y., Rayner, S., and Chen, S. 2012. Small non-coding RNA SraG regulates the operon YPK_12061205 in Yersinia pseudotuberculosis. FEMS Microbiol. Lett. 331:37-43. 
Ma, B., Hibbing, M. E., Kim, H. S., Reedy, R. M., Yedidia, I., Breuer, J., Breuer, J., Glasner, J. D., Perna, N. T., Kelman, A., and Charkowski, A. O. 2007. Host range and molecular phylogenies of the soft rot enterobacterial genera pectobacterium and dickeya. Phytopathology 97: 1150-1163.

Mandin, P., and Gottesman, S. 2010. Integrating anaerobic/aerobic sensing and the general stress response through the ArcZ small RNA. EMBO J. 29:3094-3107.

Mansfield, J., Genin, S., Magori, S., Citovsky, V., Sriariyanum, M., Ronald, P., Dow, M., Verdier, V., Beer, S. V., Machado, M. A., Toth, I., Salmond, G., and Foster, G. D. 2012. Top 10 plant pathogenic bacteria in molecular plant pathology. Mol. Plant Pathol. 13:614-629.

Mortazavi, A., Williams, B. A., McCue, K., Schaeffer, L., and Wold, B. 2008. Mapping and quantifying mammalian transcriptomes by RNASeq. Nat. Methods 5:621-628.

Mukherjee, A., Cui, Y., Ma, W., Liu, Y., and Chatterjee, A. K. 2000. hexA of Erwinia carotovora ssp. carotovora strain Ecc71 negatively regulates production of RpoS and $r \sin B$ RNA, a global regulator of extracellular proteins, plant virulence and the quorum-sensing signal, $N$-(3oxohexanoyl)-L-homoserine lactone. Environ. Microbiol. 2:203-215.

Mukherjee, A., Cui, Y., Ma, W., Liu, Y., Ishihama, A., Eisenstark, A., and Chatterjee, A. K. 1998. RpoS (sigma-S) controls expression of rsmA, a global regulator of secondary metabolites, harpin, and extracellular proteins in Erwinia carotovora. J. Bacteriol. 180:3629-3634.

Mulder, D. T., Cooper, C. A., and Coombes, B. K. 2012. Type VI secretion system-associated gene clusters contribute to pathogenesis of Salmonella enterica serovar Typhimurium. Infect. Immun. 80:1996-2007.

Nuss, A. M., Beckstette, M., Pimenova, M., Schmühl, C., Opitz, W., Pisano, F., Heroven, A. K., and Dersch, P. 2017. Tissue dual RNA-seq allows fast discovery of infection-specific functions and riboregulators shaping host-pathogen transcriptomes. Proc. Natl. Acad. Sci. U.S.A. 114: E791-E800.

O’Toole, G. A., and Kolter, R. 1998a. Flagellar and twitching motility are necessary for Pseudomonas aeruginosa biofilm development. Mol. Microbiol. 30:295-304.

O'Toole, G. A., and Kolter, R. 1998b. Initiation of biofilm formation in Pseudomonas fluorescens WCS365 proceeds via multiple, convergent signalling pathways: A genetic analysis. Mol. Microbiol. 28:449-461.

Papenfort, K., Said, N., Welsink, T., Lucchini, S., Hinton, J. C., and Vogel, J. 2009. Specific and pleiotropic patterns of mRNA regulation by ArcZ, a conserved, Hfq-dependent small RNA. Mol. Microbiol. 74:139-158.

Papenfort, K., Sun, Y., Miyakoshi, M., Vanderpool, C. K., and Vogel, J. 2013. Small RNA-mediated activation of sugar phosphatase mRNA regulates glucose homeostasis. Cell 153:426-437.

Pukatzki, S., Ma, A. T., Sturtevant, D., Krastins, B., Sarracino, D., Nelson, W. C., Heidelberg, J. F., and Mekalanos, J. J. 2006. Identification of a conserved bacterial protein secretion system in Vibrio cholerae using the Dictyostelium host model system. Proc. Natl. Acad. Sci. U.S.A. 103: 1528-1533.

Records, A. R. 2011. The type VI secretion system: A multipurpose delivery system with a phage-like machinery. Mol. Plant-Microbe Interact 24:751-757.

Robinson, K. E., Orans, J., Kovach, A. R., Link, T. M., and Brennan, R. G. 2014. Mapping Hfq-RNA interaction surfaces using tryptophan fluorescence quenching. Nucleic Acids Res. 42:2736-2749.

Schiano, C. A., Bellows, L. E., and Lathem, W. W. 2010. The small RNA chaperone $\mathrm{Hfq}$ is required for the virulence of Yersinia pseudotuberculosis. Infect. Immun. 78:2034-2044.

Sharma, C. M., Hoffmann, S., Darfeuille, F., Reignier, J., Findeiss, S., Sittka, A., Chabas, S., Reiche, K., Hackermüller, J., Reinhardt, R., Stadler, P. F., and Vogel, J. 2010. The primary transcriptome of the major human pathogen Helicobacter pylori. Nature 464:250-255.

Shen, Y., Jiang, Z., Yao, X., Zhang, Z., Lin, H., Zhao, M., Liu, H., Peng, H., Li, S., and Pan, G. 2012. Genome expression profile analysis of the immature maize embryo during dedifferentiation. PLoS One 7:e32237.

Siryaporn, A., Kuchma, S. L., O’Toole, G. A., and Gitai, Z. 2014. Surface attachment induces Pseudomonas aeruginosa virulence. Proc. Natl. Acad. Sci. U.S.A. 111:16860-16865.
Sittka, A., Pfeiffer, V., Tedin, K., and Vogel, J. 2007. The RNA chaperone $\mathrm{Hfq}$ is essential for the virulence of Salmonella typhimurium. Mol. Microbiol. 63:193-217.

Sonnleitner, E., and Bläsi, U. 2014. Regulation of Hfq by the RNA CrcZ in Pseudomonas aeruginosa carbon catabolite repression. PLoS Genet. 10: e1004440.

Thomson, N. R., Cox, A., Bycroft, B. W., Stewart, G. S., Williams, P., and Salmond, G. P. 1997. The rap and hor proteins of Erwinia, Serratia and Yersinia: A novel subgroup in a growing superfamily of proteins regulating diverse physiological processes in bacterial pathogens. Mol. Microbiol. 26:531-544.

Tian, Y., Zhao, Y., Wu, X., Liu, F., Hu, B., and Walcott, R. R. 2015. The type VI protein secretion system contributes to biofilm formation and seed-to-seedling transmission of Acidovorax citrulli on melon. Mol. Plant Pathol. 16:38-47.

Tobias, N. J., Heinrich, A. K., Eresmann, H., Wright, P. R., Neubacher, N., Backofen, R., and Bode, H. B. 2017. Photorhabdus-nematode symbiosis is dependent on $h f q$-mediated regulation of secondary metabolites. Environ. Microbiol. 19:119-129.

Toth, I. K., Bell, K. S., Holeva, M. C., and Birch, P. R. 2003. Soft rot erwiniae: From genes to genomes. Mol. Plant Pathol. 4:17-30.

Vogel, J., and Luisi, B. F. 2011. Hfq and its constellation of RNA. Nat. Rev. Microbiol. 9:578-589.

Wang, D., Korban, S. S., and Zhao, Y. 2009. The Rcs phosphorelay system is essential for pathogenicity in Erwinia amylovora. Mol. Plant Pathol. 10:277-290.

Wang, G., Huang, X., Li, S., Huang, J., Wei, X., Li, Y., and Xu, Y. 2012. The RNA chaperone Hfq regulates antibiotic biosynthesis in the rhizobacterium Pseudomonas aeruginosa M18. J. Bacteriol. 194: 2443-2457.

Wang, H., Yang, Z., Du, S., Ma, L., Liao, Y., Wang, Y., Toth, I., and Fan, J. 2018. Characterization of Pectobacterium carotovorum proteins differentially expressed during infection of Zantedeschia elliotiana in vivo and in vitro which are essential for virulence. Mol. Plant Pathol. 19:35-48.

Wang, J., Li, B., Meng, Y., Ma, X., Lai, Y., Si, E., Yang, K., Ren, P., Shang, X., and Wang, H. 2015. Transcriptomic profiling of the saltstress response in the halophyte Halogeton glomeratus. BMC Genomics 16:169.

Wang, M. C., Chien, H. F., Tsai, Y. L., Liu, M. C., and Liaw, S. J. 2014. The RNA chaperone $\mathrm{Hfq}$ is involved in stress tolerance and virulence in uropathogenic Proteus mirabilis. PLoS One 9:e85626.

Wang, W., Wang, L., Zou, Y., Zhang, J., Gong, Q., Wu, J., and Shi, Y. 2011. Cooperation of Escherichia coli Hfq hexamers in DsrA binding. Genes Dev. 25:2106-2117.

Wilf, N. M., Reid, A. J., Ramsay, J. P., Williamson, N. R., Croucher, N. J., Gatto, L., Hester, S. S., Goulding, D., Barquist, L., Lilley, K. S., Kingsley, R. A., Dougan, G., and Salmond, G. P. C. 2013. RNA-seq reveals the RNA binding proteins, Hfq and RsmA, play various roles in virulence, antibiotic production and genomic flux in Serratia sp. ATCC 39006. BMC Genomics 14:822.

Wilms, I., Möller, P., Stock, A. M., Gurski, R., Lai, E. M., and Narberhaus, F. 2012. Hfq influences multiple transport systems and virulence in the plant pathogen Agrobacterium tumefaciens. J. Bacteriol. 194:5209-5217.

Wroblewska, Z., and Olejniczak, M. 2016. Hfq assists small RNAs in binding to the coding sequence of $o m p D$ mRNA and in rearranging its structure. RNA 22:979-994.

Yasuhara-Bell, J., Marrero, G., De Silva, A., and Alvarez, A. M. 2016. Specific detection of Pectobacterium carotovorum by loop-mediated isothermal amplification. Mol. Plant Pathol. 17:1499-1505.

Zeng, Q., McNally, R. R., and Sundin, G. W. 2013. Global small RNA chaperone $\mathrm{Hfq}$ and regulatory small RNAs are important virulence regulators in Erwinia amylovora. J. Bacteriol. 195:1706-1717.

\section{AUTHOR-RECOMMENDED INTERNET RESOURCE}

Rfam website: http://www.sanger.ac.uk/Software/Rfam 